\title{
Employment Time and the Cyclicality of Earnings Growth*
}

\author{
Eran Hoffmann ${ }^{\dagger} \quad$ Davide Malacrino ${ }^{\ddagger}$
}

February 15, 2016

\begin{abstract}
The cross-sectional distribution of log annual earnings growth becomes more negatively skewed during recessions. However, earnings growth is the sum of changes in employment time (weeks of employment within a year) and changes in earnings rate (weekly earnings). Distinguishing between the two sources of variation is important for interpreting the cyclical patterns of earnings growth. We use administrative data from Italy and survey data from the United States to disentangle the role of employment time in shaping the distribution of earnings growth. We find that year-to-year changes in employment time are responsible for almost all of the tail observations (bellow the 10th and above the 90th percentile), and generate more than four-fifths of the observed cross-sectional variance of earnings growth. Moreover, changes in employment time account for the cyclical properties of the skewness of the earnings growth distribution: the skewness of earnings growth is positively correlated with GDP growth but the correlation disappears when controlling for the skewness of changes in employment time. We show that the cyclicality of aggregate labor market conditions, including the separation rate and the hiring rate, explains the negative skewness of earnings growth during recessions.
\end{abstract}

\footnotetext{
${ }^{*}$ We thank Monika Piazzesi and Luigi Pistaferri for valuable guidance. We also thank Nick Bloom, Raj Chetty, Mark Duggan, Fatih Guvenen, Caroline Hoxby, Moritz Lenel, Serdar Ozkan, Petra Persson, Itay Saporta-Ecksten, Chris Tonetti, Alonso Villacorta, and seminar participants at Stanford University for helpful comments.

${ }^{\dagger}$ Department of Economics, Stanford University. Email: eranhoff@stanford.edu.

${ }^{\ddagger}$ Department of Economics, Stanford University. Email: davidem@stanford.edu
} 


\section{Introduction}

A long strand of literature has studied and quantified the individual labor earnings process, and in particular earnings growth. ${ }^{1}$ In a recent paper Guvenen, Ozkan, and Song (2014) (GOS from now on) use a large administrative dataset from the US Social Security Administration and find that the volatility in individual earnings is counter cyclical. In particular, the dispersion of annual earnings growth is larger during recessions than during expansions, and the skewness of earnings growth is negative and pro-cyclical. Hence, large reductions in individual earnings are more common than large increases, and this asymmetry of the distribution is more pronounced during recessions. These findings are important for a broad class of economic applications in which workers or households face idiosyncratic risk - such as the design of social insurance, analysis of the business cycle and asset pricing. ${ }^{2}$

However, the dataset used by GOS and by others does not contain observations of the time spent in employment within a given year, or the earnings rate when employed. ${ }^{3}$ Consider the decomposition of individual $i$ 's (log) annual earnings growth $\Delta y_{i t}$, into the change in the (log) employment time $\Delta x_{i t}$ (i.e weeks or months of employment), and the change in (log) earnings rate $\Delta w_{i t}$ (i.e weekly or monthly earnings):

$$
\Delta y_{i t}=\Delta x_{i t}+\Delta w_{i t}
$$

Decomposition (1) implies that a change in earnings could be the outcome of either changes in employment time or changes in earnings rate (or both). This distinction is important for two main reasons. First, to the degree that volatility in earnings represents risk, each source of variation has different policy implications. For example, unemployment insurance may be effective in insuring risk coming from employment time, but ineffective in insuring risk coming from earnings rate. Similarly, wage insurance policies, such as the one suggested by LaLonde (2007), can limit the risk coming from earnings rate but not from employment time. Second, in some applications one of the components is exogenous (at least from the perspective of the household), while the other is considered a response margin. The canonical real business cycle model, for instance, assumes that households take wages as given, and respond by adjusting labor supply. ${ }^{4}$

\footnotetext{
${ }^{1}$ See for instance MaCurdy (1982), Abowd and Card (1989), Meghir and Pistaferri (2004), Storesletten, Telmer, and Yaron (2004a), Storesletten, Telmer, and Yaron (2004b), Guvenen (2009).

${ }^{2}$ Constantinides and Duffie (1996), Krusell and Smith (1997), Storesletten, Telmer, and Yaron (2007) are examples of papers that look at the role of countercyclical variance in incomplete asset markets. Mankiw (1986), Brav, Constantinides, and Geczy (2002), Kocherlakota and Pistaferri (2009) stress the role of countercyclical left skewness of shocks. In more recent work Golosov et al. (2013), Constantinides and Ghosh (2014) account for the skeweness of risk in models of dynamic optimal taxation and asset pricing respectively.

${ }^{3}$ The Master Earnings File (MEF) data from the US Social Security Administration used by GOS and by others is based on reported income from W-2 tax forms. See for example Song and Manchester (2007), von Wachter, Song, and Manchester (2011) and French and Song (2014). For a discussion of advantages and limitations of these data see Kopczuk, Saez, and Song (2010).

${ }^{4}$ For instance, Hansen (1985) and Rogerson (1988) model households as choosing employment, and taking wage rate as given.
} 
Motivated by these considerations, we ask whether the cyclicality in earnings growth found in GOS can be explained by changes in employment time. We answer this question in three parts. First, we show that most of the cross-sectional variation in earnings growth is due to changes in employment time, rather than changes in earnings rate. Second, we decompose the cyclical patterns of earnings growth into its components and provide quantitative and visual evidence for the dominant role of employment time in generating these patterns. Third, we explore a mechanism that maps aggregate labor market conditions into the distribution of changes in employment time, and show that high separation rate and low hiring rate contribute to the negative skewness of changes in employment time during recessions.

We use a large administrative panel dataset from the Italian social security institute (INPS), covering the period 1985-2012. This dataset includes observations of earnings and the number of weeks worked within a given year for each worker, allowing us to perform decomposition (1) at the worker-year level. Using the INPS dataset, we are able to replicate the main findings from GOS, both in terms of shape and in terms of cyclicality of the cross-sectional distribution of earnings growth, despite the differences in labor market institutions between Italy and the United States.

We find that the tails of the earnings growth distribution (below the 10th and above the 90th percentile), are almost entirely driven by employment time: workers who are employed for a 52 weeks in a given year are 12 times less likely than those who are not to increase their earnings by more than the 90th percentile in the following year (approximately 20 percent increase). Similarly, workers who are employed for a 52 weeks in a given year are 20 times less likely than those who are not have decreased their earnings by more than the 10th percentile from the following year (approximately 20 percent decrease). Measured in logs, the decomposition of the cross-sectional variance of earnings growth in Italy reveals that changes in employment time generate more than four-fifths of the variance in annual earnings growth (see Figure 1). Employment time is the primary source of variation in earnings growth across individuals.

Then, we decompose the cyclicality of earnings growth. In particular, we are interested in accounting for the cyclical asymmetry pointed out by GOS, as measured by the third moment of the cross-sectional distributions. We construct time series of the first three moments of earnings growth and each of its components using the INPS data. The time series of the third moment of changes in employment time is similar to the time series of third moment of earnings growth, both in magnitude and in pattern, while the third moment of changes in earnings rate is relatively flat and close to zero. These time series provide evidence that the cyclical asymmetry in earnings growth is driven by changes in employment time rather than changes in earnings rate. 
We extend our analysis to include evidence from the US, to study the mechanism that generates the asymmetry in changes in employment time during recessions. In the absence of observations of employment time in administrative data for the US, we construct implied cross-sectional distributions of annual employment time by applying a Markov chain statistical model to monthly frequency labor market flows. Under the Markov assumption, transitions between labor market states (employment, unemployment, not-in-the-labor-force) are independent over time, conditional on the aggregate state of the economy. This assumption allows as to tractably recover the crosssectional distributions of changes in employment time at a monthly frequency and construct a time series of their central moments. We find that the implied distributions in the US and the observed distributions in Italy have similar dynamic properties. As was observed in Italy, the moments of the implied distributions of changes in employment time move together with the moments of earnings growth provided by GOS.

The implied distributions suggest a mechanism amplifying negative changes in employment time in recessions. During recessions the separation rate (the probability to transition from employment to unemployment) goes up and the hiring rate (the probability to transition from unemployment to employment) goes down. High separation rate increases the number of workers who experience a reduction in employment time, while low hiring rate extends the duration of unemployment spells. Together, these two factors make large negative changes in employment time more common and, measured in logs, generate asymmetry in the cross-sectional distribution of changes in employment time.

Using the constructed time series from Italy and the US, and the time series provided by GOS, we conduct a final quantitative exercise to check whether changes in employment time can account for the cyclicality of earnings growth. We find that the skewness of earnings growth, capturing the asymmetry of the distribution, is highly correlated with GDP growth, but this correlation disappears when controlling for the skewness of changes in employment time. We interpret this result as employment time generating the cyclical asymmetry of earnings growth.

Throughout our analysis we remain agnostic about what part of the cross-sectional dispersion represents risk, and what part of it is anticipated or determined by choices of workers. However, for applications with forward looking agents this distinction is crucial. We separately discuss the risk in each component of decomposition (1). The dispersion of changes in earnings rate includes differences in individual specific anticipated growth (determined, among other things, by age and education), transitory shocks, permanent shocks and measurement error. Administrative records are generally poor in controls for the determinants of the individual specific anticipated growth, and thus are not ideal for disentangling the components of risk. Moreover, since we find that changes in earnings rate are relatively less skewed and less cyclical than annual earnings growth, models of wage risk with symmetric shocks and a stationary environments are not ruled out. Therefore studies that rely on these assumptions and use rich panel datasets may more accurately capture idiosyncratic earnings rate risk (e.g Meghir and Pistaferri (2004) and Guvenen (2009)). 
The relationship between dispersion of changes in employment and employment risk raises different considerations. First, difference in logs is not the best measure of employment risk. ${ }^{5}$ A better way to measure employment risk would be, following the literature and our analysis, to directly measure the separation rate and the hiring rate and construct models that incorporate an idiosyncratic employment process. Second, the distinction between quits (voluntary separations) and layoffs (involuntary separations) is important to understand employment risk. The empirical evidence suggests that quits decrease during recessions, and so layoffs alone explain the cyclical pattern of separation rate (see for example Davis, Faberman, and Haltiwanger (2012)). Thus, by assuming all separations are involuntary, employment risk is overestimated, but its cyclicality may be underestimated.

The rest of the paper is organized as follows. Section 3 describes the theoretical framework behind the decomposition of earnings growth into changes in the employment time and changes in earnings rate. Section 2 discusses the related literature. Section 4 presents the datasets used in this paper. Sections 5 and 6 report and discuss the evidence from Italy and from the United States respectively. Section 7 presents a quantitative exercise for accounting for the cyclicality of earnings growth. We present our conclusions in Section 8.

\section{Related Literature}

This paper is directly related to studies that explore the cyclical properties of the idiosyncratic earnings process. Using PSID data, Storesletten, Telmer, and Yaron (2004b) explore the relationship between the aggregate economy and the idiosyncratic earnings risk faced by households. They find earnings growth in recessions has a higher cross sectional variance than in expansions. Guvenen, Ozkan, and Song (2014) find that the first and third moments of the cross-sectional distribution of earnings growth are even more cyclical than the second moment. Using a large administrative dataset, they find that the earnings growth distribution in the US has heavy left and right tails, and that there is considerable asymmetry in this distribution. In our study we find similar cyclical patterns in Italy, and are also able to decompose these pattern into employment time and earnings rate. This decomposition reveals a dominant role for employment time in statistically generating the cyclical patterns, and provides a new interpretation to the evidence in GOS. We view this as the main contribution of this paper.

\footnotetext{
${ }^{5}$ For a short enough period, employment time may be zero, and thus difference in logs may not be well defined. Difference in logs also does not distinguish between frequent short spells of unemployment and infrequent long spells, which may have different implications.
} 
Figure 1: Log-densities of Earnings and Earnings Rate in Italy

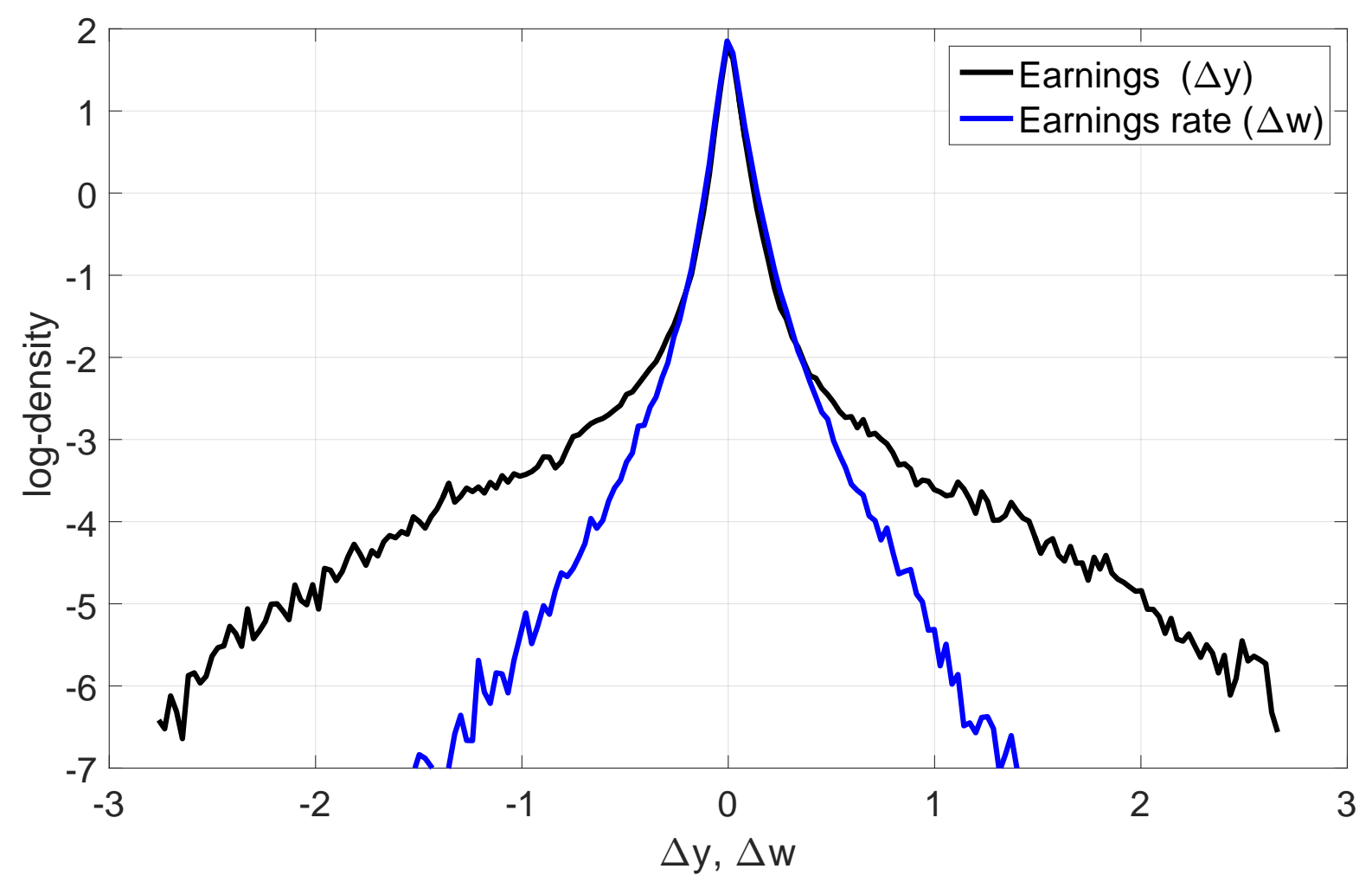

Notes: Based on a representative sample of males 25-60 that includes 300,000 observations (approximately 6.5\% of all male employees in the private sector in that age range), for the years 1995-1996. Earnings rate is the average monthly earnings. 
This paper is also related to a large literature that studies the process of individual and household level earnings using panel data. In an early work, MaCurdy (1982) uses PSID data to quantify the earnings process, and finds that a random walk around a time dependent profile is a reasonable description of the data. Abowd and Card (1989) look at the variance-covariance structure of wages and hours over time and find additional support for the random walk hypothesis. The heterogeneity of the income process across individual is studied in Meghir and Pistaferri (2004), who estimate the earnings process allowing for conditional heteroskedasticity, and find high persistence of the variance of permanent shocks. More recently, Guvenen (2009) tests whether workers follow heterogeneous income profiles or follow a common life-cycle profile with idiosyncratic risk. He finds evidence for the former, and adjusts the measurement of risk accordingly.

Many economic applications rely on idiosyncratic risk to explain household behavior and, through aggregation, its impact on the macro economy. Storesletten, Telmer, and Yaron (2004a) use idiosyncratic risk to explain why consumption inequality is increasing over the life-cycle, but not as much as income inequality. Constantinides and Duffie (1996) propose an explanation for the equity premium puzzle that relies on persistent idiosyncratic risk in the earnings process. They argue that an earnings process that has permanent shocks with infinite horizon agents can generate this pattern. Storesletten, Telmer, and Yaron (2007) extend Constantinides and Duffie (1996) by adding a life-cycle savings problem and find that this can explain even more of the equity premium puzzle. Low, Meghir, and Pistaferri (2010) study welfare programs in an environment with idiosyncratic employment and wage risks and find that job arrival and job destruction, in addition to wage shocks, have large effects on household welfare. Other applications stress the role of cyclicality in asymmetric downside risk. Schmidt (2016) studies the impact of asymmetric downside risk in earnings during recessions to explain asset prices. We inform this literature by decomposing the variation in earnings into employment time and earnings rate. While we do not explicitly take a stand on what share of these variations constitute "risk", we do measure their relative sizes. We find that employment time is the primary source of the cross-section variance of earnings growth (measured in logs), and should therefore be carefully modeled in such applications.

Finally, this paper builds on a literature that studies changes in job creation and job destruction over the business cycle using labor market flows data. Abowd and Zellner (1985), Blanchard and Diamond (1989) and more recently Shimer (2012) provide methods to recover labor market flows from survey data, and point to a pronounced counter cyclicality in the separation rate, and procyclicality of the hiring rate. In this paper we show that the cyclical properties of the separation rate and the hiring rate explain the cyclical patterns in GOS. In particular, the combination of higher risk to lose a job, together with a lower hazard rate out of unemployment during recessions contributes to a counter cyclical downside employment risk.

\section{Decomposing Earnings Growth}

In this section we discuss the decomposition of annual earnings into employment time and earnings rate and we provide some useful definitions for the rest of the analysis. 


\subsection{The Components of Earnings}

Annual earnings can be separated into three components: employment time (time spent in employment spells, sometimes referred to as the extensive margin), hours worked per unit of employment time (sometimes referred to as the intensive margin) and the mean wage per hour worked. For individual $i$ at time $t$, these three components form the following accounting identity:

$$
Y_{i t}=X_{i t} \cdot H_{i t} \cdot \tilde{W}_{i t}
$$

where $X_{i t}$ is employment time, $H_{i t}$ is hours worked per unit of employment time and $\tilde{W}_{i t}$ is the mean hourly wage. Letting the unit of time be weeks, $X_{i t}$ is measured by the number of weeks within the year spent in employment and $H_{i t}$ by the average number of hours worked per week of employment. ${ }^{6}$

By taking logs and first differencing, we get the following decomposition:

$$
\Delta y_{i t}=\Delta x_{i t}+\Delta h_{i t}+\Delta \tilde{w}_{i t}
$$

where lowercase denotes logged values, and $\Delta$ is the difference between year $t$ and year $t-1$.

In many cases, a direct observation on all three components is absent. The US administrative data from the SSA used by GOS, for instance, contain observations of $\Delta y$, but not of any of its components. In the INPS data used in this paper, earnings growth, $\Delta y$, and changes in employment time, $\Delta x$, are observed, but changes in number of hours worked per week and hourly wages are not. Given this limitation of the data, we adopt the decomposition in equation (1), in which the mean hours per week and the hourly wage are combined, $\Delta w=\Delta h+\Delta \tilde{w}$, and refer to it as changes in earnings rate:

$$
\Delta y_{i t}=\Delta x_{i t}+\Delta w_{i t}
$$

The change in earnings rate is less straightforward to understand than the change in mean hourly earnings $(\Delta \tilde{w})$. Earnings rate confounds a potentially endogenous decision margin (hours per month) with the hourly wage, thus $\Delta w$ cannot be interpreted as a change in "prices" as do hourly wages. Nonetheless, $\Delta w$ captures changes over a frequency that is typical of employment contracts, often denominated in weekly, monthly or even annual terms rather than hourly pay. In addition, labor economists have found responses in the intensive margin of male workers to be smaller than adjustments in the extensive margin. ${ }^{7}$

\footnotetext{
${ }^{6}$ To give an example, a worker who worked for 39 out of 52 weeks, 40 hours per week (on average) and earned $\$ 20$ an hour (on average), would earn $\$ 31.2 \mathrm{~K}$ in a given year. i.e $X_{i t}=39, H_{i t}=40, \tilde{W}_{i t}=\$ 20$ and $Y_{i t}=39 \cdot 40 \cdot \$ 20=$ $\$ 31,200$.

${ }^{7}$ Most recently, Blundell et al. (2011) find that the elasticity of labor supply on the extensive margin is higher than on the intensive margin across countries. Chetty (2012) argues that even a small adjustment cost can explain the rigidity of labor supply on the intensive margin. Notice that in some cases, particularly during recessions, changes in the extensive margin may be involuntary.
} 


\subsection{Decomposing Moments of the Cross-Sectional Distribution}

In our analysis, we are interested in quantifying the role of $\Delta x$ in generating both the cross-sectional moments of the distribution of $\Delta y$ and their variations with the business cycle. More specifically, we would like to measure the contribution of each component to the first three central moments, since these are measures commonly used to describe distributions. We will also discuss the potential of decomposing skewness (standardized third central moment) and quantile based skewness measures.

Before we start, some notations are in order. We denote the $j$ th central moment of the crosssectional distribution as $m_{j}(\cdot)$, and $m_{k, l}(\cdot, \cdot)$ as the cross-term of order $k$ and $l$, that is:

$$
m_{k, l}(a, b) \equiv \mathrm{E}^{i}\left[\left(a-m_{1}(a)\right)^{k}\left(b-m_{1}(b)\right)^{l}\right]
$$

for any two random variables $a$ and $b$, and where the superscript $i$ indicates that the expected value is taken with respect to individuals in a single cross-section. Here are the decompositions of the first three central moments.

Mean. The first moment of the distribution has a additive decomposition:

$$
m_{1}(\Delta y)=m_{1}(\Delta x)+m_{1}(\Delta w)
$$

Variance. The second central moment of $\Delta y$ can be decomposed to a sum of the second moments of its components and an additional cross-term.

$$
m_{2}(\Delta y)=m_{2}(\Delta x)+2 m_{1,1}(\Delta x, \Delta w)+m_{2}(\Delta w)
$$

The cross term for the variance decomposition is two times the covariance. If the covariance is small in magnitude (such as in the case when $\Delta x$ and $\Delta w$ are mean-independent) we can measure the approximate contribution of each component as their share of the variance.

Third Moment. The third central moment expands to four terms:

$$
m_{3}(\Delta y)=m_{3}(\Delta x)+3 m_{2,1}(\Delta x, \Delta w)+3 m_{1,2}(\Delta x, \Delta w)+m_{3}(\Delta w)
$$

In the analysis that follows we will refer to the sum $3 m_{2,1}(\Delta x, \Delta w)+3 m_{1,2}(\Delta x, \Delta w)$ as the cross term of the third moment. Neglecting the cross term, the decomposition of the third central moment of earnings growth is just the sum of the third central moment of its components.

\subsection{Additional Moments}

Two additional moments are sometimes preferred in the literature to describe asymmetry: standardized skewness and quantile based skewness.

Standardized skewness is the third moment of a standardized random variable. Its advantage over the non-standardized third central moment is that it is a scale-free measure of the asymmetry of the distribution. ${ }^{8}$ The formal definition of skewness is given by:

\footnotetext{
${ }^{8}$ Consider the random variable $Z$ and a scaling constant $\alpha$. If it exists, the skewness of $Z$ and $\alpha Z$ will be the same, while the third central moment will not.
} 


$$
\operatorname{Sk}(\Delta y)=\frac{m_{3}(\Delta y)}{\left(m_{2}(\Delta y)\right)^{3 / 2}}
$$

Decomposition of the skewness of earnings growth into the skewness of its components is less elegant than the decomposition of the third central moment in (7):

$$
\begin{aligned}
\operatorname{Sk}(\Delta y)=\left(\frac{m_{2}(\Delta x)}{m_{2}(\Delta y)}\right)^{3 / 2} \operatorname{Sk}(\Delta x)+\left(\frac{m_{2}(\Delta w)}{m_{2}(\Delta y)}\right)^{3 / 2} \mathrm{Sk}(\Delta w)+ & \\
& +3 \frac{m_{2,1}(\Delta x, \Delta w)}{m_{2}(\Delta y)^{3 / 2}}+3 \frac{m_{1,2}(\Delta x, \Delta w)}{m_{2}\left(\Delta y_{i t}\right)^{3 / 2}}
\end{aligned}
$$

In equation (9), the skewness of each component is scaled by a function of the ratio of variances. This non-trivial scaling makes the visual presentation of this decomposition less appealing, because the skewness of the components does not add up to the skewness of earnings growth. Moreover, if the relative variances of the components is not varying much (as in our case), this decomposition is the same as a weighted decomposition of the third moment.

Another way of measuring asymmetry that is sometimes used in the literature is based on quantiles. One of these measures is Kelly's skewness, which uses the 10, 50 and 90 percentiles of the distribution, and is preferred by GOS. Its formal definition is the following:

$$
\frac{\left(P_{90}(\Delta y)-P_{50}(\Delta y)\right)-\left(P_{50}(\Delta y)-P_{10}(\Delta y)\right)}{P_{90}(\Delta y)-P_{10}(\Delta y)}
$$

where $P_{n}$ refers to the $n$th percentile of the cross-sectional distribution.

As opposed to central moments, quantiles always exist, they are measured accurately in small samples, and unless $P_{10}=P_{90}$, the measure is always well defined on the interval $[-1,1]$. However this measure is somewhat less useful for our analysis for several reasons. First, compared to skewness, quantile based measures overweight specific parts of the distribution that may not be particularly important. Even if the chosen quantiles are good at describing the distribution of one variable, that property may not carry over to the components of that variable (the 90th quantile of earnings growth does not correspond to the 90th quantile of earnings rate). Thus quantile based measures do not lend themselves to a decomposition similar to (5), (6) and (7), without making strict parametric assumptions. Second, both skewness and Kelly's skewness are scale free measures, hence they describe the shape, but not the magnitude of the distribution. Any statement regarding the relative importance of employment time and earnings rate would require taking into account the magnitude of these components. 


\section{Data}

Before turning to the analysis, we describe our data sources: Italian social security data (INPS), Current Population Survey (CPS) data for the United States and moments of earnings growth from Guvenen, Ozkan, and Song (2014). ${ }^{9}$

\subsection{Italy: INPS Data}

The Italian social security administration (Istituto Nazionale di Previdenza Sociale or INPS) collects data on employer and employee relationship in order to compute social contribution and pension benefits. We use a sample dataset covering the period 1985-2012, based on workers who were born in 24 randomly selected birth dates from the universe of all the Italian employees in the nonfarm private sector, who are insured at INPS. ${ }^{10}$ The data represents a 6.6 percent sample of this population.

The basic observation in the raw data is a job relationship with a private employer within a calendar year. For every job relationship we observe contributive earnings which include both salary and non-salary components, and the number of weeks the earnings refer to. ${ }^{11}$ The earnings from each job relationship are top-coded in accordance with a daily cap of $€ 650$ in 2013 (equivalent to individual annual earnings of more than $€ 200 \mathrm{~K}$ ). We found that this cap affects at most 0.5 percent of all matched observations, and when excluded from our analysis, the results do not change. For a discussion of the effect of top coding, see Appendix A.

We obtain an individual level panel including joint observation of annual earnings and weeks of work by performing the following steps. First, we combine information from multiple jobs for the same individual summing over all records associated with the same worker in a given year. This gives us the annual earnings of that worker. We adjust earnings using the CPI and compute the difference in logs to get earnings growth $\Delta y_{i t}$. Second, we calculate employment time as the number of weeks worked - the minimum between 52 weeks and the sum of all weeks worked across all jobs within a calendar year. ${ }^{12}$ We take the difference in logs across every two consecutive years in which the worker is observed to get the changes in employment time $\Delta x_{i t}$. Lastly, we take the difference between earnings growth, and changes in employment time, to recover the change in earnings rate

\footnotetext{
${ }^{9}$ We also use timeseries of GDP growth and CPI from NIPA tables (US) and from the Italian National Institute of Statistics (Italy).

${ }^{10}$ We use the LoSai dataset made available by the Italian Ministry of Labor and Social Policy. More information can be found at www.cliclavoro.gov.it

${ }^{11}$ Contributive earnings include the earnings used to compute individual contributions to the social security system (imponibile previdenziale) and are different from the taxable earnings (imponibile fiscale) as the social security contributions are included in the former but excluded in the latter. While over-time pay is included, some lump sum payments, such as severance payments, are excluded.

${ }^{12}$ If a worker held two jobs at the same time we would not capture it with this data. However, for a sub sample of workers we are also able observe the exact number of months worked, correctly accounting for overlapping jobs. We redo our calculations on this subsample and find that our results are quantitatively very similar and qualitatively unchanged.
} 
$\Delta w_{i t}$ (change in mean weekly earnings earnings):

$$
\Delta w_{i t} \equiv \Delta y_{i t}-\Delta x_{i t}
$$

For comparability to the analysis in GOS, we restrict the sample to 25-60 years old male workers, who have a record both in year $t$ and $t-1$ with earnings above the 2.5 percentile of the income distribution, and who have worked for at least 3 weeks in a given year. ${ }^{13}$ We also restrict the sample to employees whose main work contract is full time. ${ }^{14}$ Including part-time workers does not change the main results, and dropping these observations reduces the concerns that variation in average weekly earnings could be in fact driven by large changes in hours worked within a week.

We are left with an unbalanced panel of 974,686 workers over 27 years with a total of more than 9 million individual-year observations. In every particular two year period, we have 335,000 observations on average. Workers appear in the sample for 9.7 years on average, and the median worker spends 8 years in the sample. More descriptive statistics about the age and the level of annual earnings, earnings rate and employment time are reported in Table 1 where all years are pooled together. ${ }^{15}$ Mean annual earnings are $€ 27,988$ and most workers are employed for the full year (the median worker is employed for 52 weeks). Earnings rates (weekly earnings) range between $€ 321$ at the 10 th percentile to $€ 896$ at the 90 th percentile. Annual earnings growth (in log points) is much more disperse than earnings rate growth: the standard deviation of $\Delta y$ is over two times the standard deviation of $\Delta w(0.40$ and 0.17 respectively).

Figure 2 compares the log-density of earnings growth, $\Delta y_{i t}$, in Italy and the United States, for the year 1996. ${ }^{16}$ Both distributions display the same qualitative features: heavy left and right tail and left skewness. The Italian distribution turns out to be less dispersed and, at least in that year, more symmetric. Note that due to a smaller sample size the the data used by GOS (approximately 300 thousand observations per year) we cannot reliably estimate densities of earnings growth in excess of $-2.5 /+2.5 \log$ points (12 times increase or decrease). These similarities imply that the forces driving the particular shape of the distribution are not unique to the United States, and support the external validity of the analysis using the Italian data.

\footnotetext{
${ }^{13}$ The 2.5 percentile is equivalent to an annual income of $€ 800$ in 2012 (alternative choices do not affect the results significantly). There is no minimum wage in Italy, therefore the equivalent definition to GOS (one-half of 260 hours of minimum wage) is not applicable. Removing workers who have worked less than 3 weeks corresponds to that definition, and reduces the measurement error in earnings rate.

${ }^{14}$ Full-time and part-time employment is specified at the record level. We define main work contract to be the one associated with the highest share of overall earnings in a year.

${ }^{15}$ See Appendix A for summary statistics for selected years. Year by year statistics are available from the authors upon request. In the appendix table A.2, we also report more statistics for all the years in the sample.

${ }^{16}$ The density data for the United States is taken from Guvenen, Karahan, Ozkan, and Song (2015).
} 
Table 1: Summary Statistics - the INPS Panel Data

\begin{tabular}{lrrrrr}
\hline & Mean & Std.Dev. & P10 & P50 & P90 \\
\hline Age & 40.71 & 9.04 & 29.00 & 40.00 & 54.00 \\
Annual Earnings & 27,988 & 18,919 & 12,181 & 23,905 & 45,565 \\
Employment Time (Weeks) & 48.20 & 9.77 & 36.00 & 52.00 & 52.00 \\
Earnings Rate (Weekly Earnings) & 572 & 360 & 321 & 474 & 896 \\
\hline$\Delta$ Earnings $(\Delta y)$ & 0.01 & 0.40 & -0.20 & 0.01 & 0.22 \\
$\Delta$ Employment Time $(\Delta x)$ & -0.01 & 0.38 & -0.10 & 0.00 & 0.08 \\
$\Delta$ Earnings Rate $(\Delta w)$ & 0.02 & 0.17 & -0.10 & 0.01 & 0.15 \\
\hline
\end{tabular}

Observations: 9293543

Notes: The sample is restricted to 25-60 years old males with at least one record at the Italian social security administration between 1985 and 2012. Earnings data are in 2013 euros. $\Delta$ terms are in logs. Source: INPS, see details in text.

\subsection{US Data}

For our analysis of the US earnings dynamics, we complement moments of cross-sectional distributions of earnings growth, made available by GOS, with implied cross-sectional distributions of changes in employment time, that we recover from survey data on monthly labor market flows from the Current Population Survey.

\subsubsection{Moments from GOS}

Guvenen, Ozkan, and Song (2014) provide time series of moments that are used in our analysis. They are based on a large panel dataset on earnings histories from the US Social Security Administration records, the Master Earnings File (MEF). The moments are computed from a 10 percent sample of males, 25-60 years old, covering the period 1978-2011. As this dataset is based on official W-2 forms reporting taxable labor income, it is generally considered reliable (see Kopczuk, Saez, and Song (2010) for a discussion of advantages and limitations of these data). However it does not contain any information about employment spells or other sources of income (such as from unemployment insurance). For a detailed description of the data and sampling method see Guvenen et al. (2014) section II and references therein. We use the first three moments from their appendix tables A.1 and A.8 for our analysis.

\subsubsection{CPS Data}

We use CPS matched monthly files, collected by the Bureau of Labor Statistics and made available on-line by IPUMS-CPS (Flood et al., 2015). We follow a standard procedure to recover the monthly transition probabilities. 
Figure 2: Log-Density of Earnings Growth, Italy and US 1996

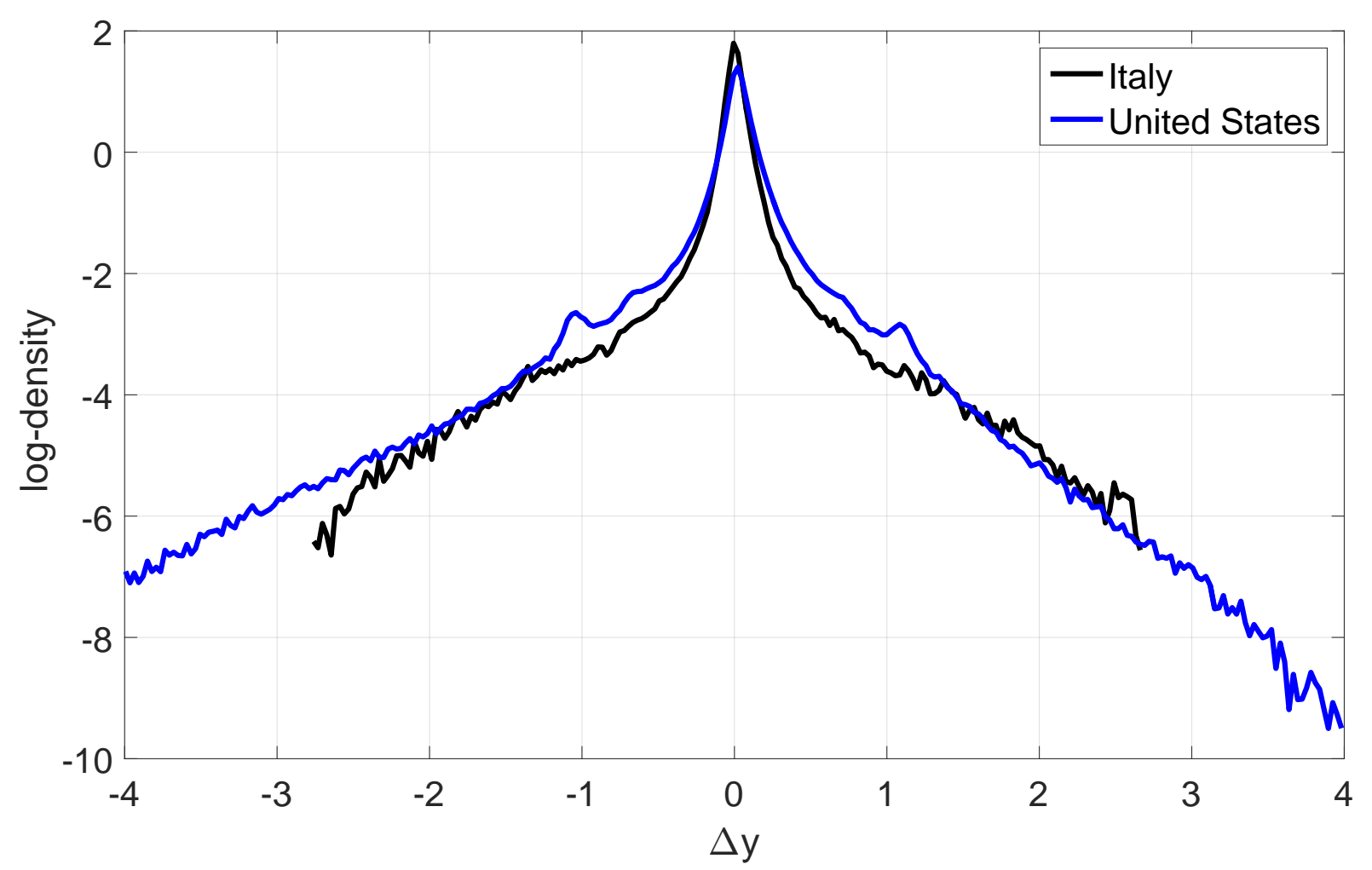

Sources: Italy - INPS (as described in the main text). United States - Guvenen et al. (2015). All samples are restricted to males 25-60 years old.

Our sample covers the period 1989-2013 ${ }^{17}$. We restrict observations to males 25-60 years old, for consistency across samples. Each observation is a person-month record, including the employment state in the previous month and the employment state at the current period. All the statistics in this paper are weighted using the "final weight" provided by the BLS. Standard errors are computed using 500 bootstrapped samples. The share of the sample at each of the three states, and additional descriptive statistics are in Table A.3 in appendix A.

\footnotetext{
${ }^{17}$ Due to technical issues with the consistency of household identifiers, the months between May and September 1995 cannot be matched. We exclude this period, and the following and previous 12 months from our analysis.
} 
We distinguish between three labor market states: Employed (E), Unemployed (U) and Notin-labor-force $(\mathrm{N})$. Figure 3 displays the shares of the three states over time. Several details are worth mentioning. The most striking is the large change in employment and unemployment during the Great Recession (2008-2009). This shift, translated into individual level changes in employment time, generated large negative shocks to earnings for many workers. Unemployment share ${ }^{18}$ increased to almost twice its typical value in the 24 years of the sample, reaching $9.2 \%$ in January 2010, a month that was officially part of the recovery phase.

It is also important to notice that not-in-labor-force $(\mathrm{N})$ state follows a long-term upward trend. The share of working age males that are not participating in the labor force has increased from 7.6\% in Jan 1990 to $13.7 \%$ in Dec 2013, the last month in the sample, which is also the peak month. This rise has been noticed most clearly during the great recession, and has typically been classified as reflecting "discouraged workers", but can also reflect a change in the composition of workers. According to Hall (2014) this pattern is part of a trend that is unrelated to the business cycle. In any case, this trend is quantitatively important and is reflected in our analysis.

Lastly, there is a considerable amount of seasonality in the data. The series we use are not seasonally adjusted, since seasonality of employment within the year may be quantitatively important as a source of variation. Our analysis is based on moments of annual changes in employment time, in a monthly frequency, potentially uncovering seasonality in the distribution of changes in employment time.

\section{Evidence from Italy}

In this section we decompose the earnings growth into changes in employment time and changes in earnings rate at the individual worker level using the INPS data. We divide our analysis into two parts: evidence from the cross section, where we study the cross-sectional distribution of earnings growth, and time-series evidence where we study the cyclical patterns of earnings growth.

\subsection{Evidence from the Cross Section}

Figure 1 in the introduction, displays the log densities of earnings growth and monthly earnings for the year 1996. The graph shows that the distribution of changes in earnings rate has thinner tails than that of earnings growth. We expand the analysis of the cross-sectional distribution of earnings growth, and find that changes in employment time are the main source of variation in the cross section of earnings growth. We do so first non-parametrically by exploring the joint distribution of earnings growth and changes in employment time, then we conduct variance decomposition of earnings growth to find their relative contributions of employment time and earnings rate.

\footnotetext{
${ }^{18}$ It is important to notice that unemployment share does not correspond to the unemployment rate - the denominator for the unemployment rate is the civilian labor force (employed plus unemployed) while the share is denominated by the total working age population of males.
} 
Figure 3: Labor Market State Shares, US 1989-2013
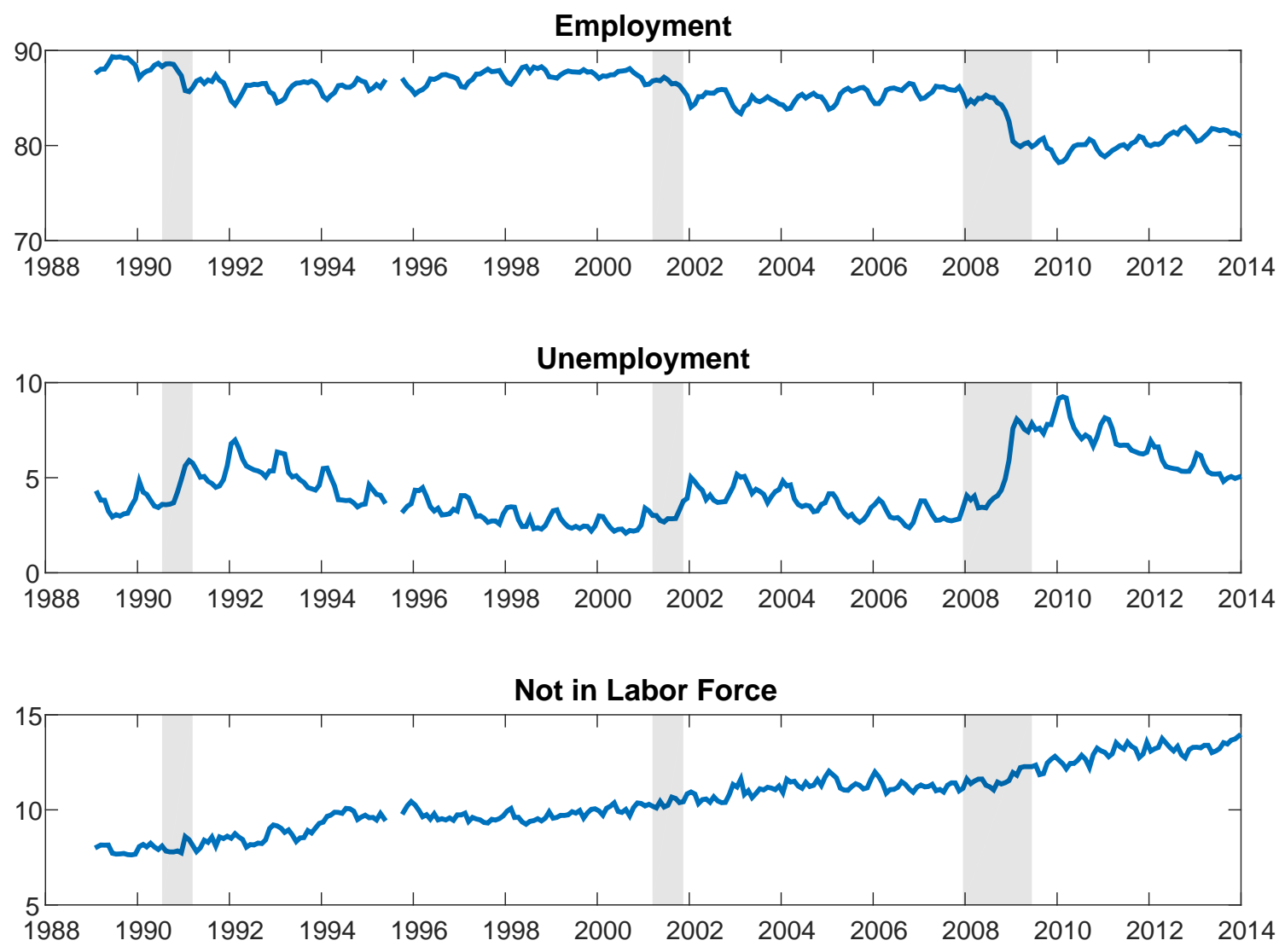

Notes: Sample includes males 25-60 years old that appear in two consecutive months, and are matched using CPSIDP identifier. Sources: IPUMS-CPS (Flood et al., 2015).

Our preferred way to explore the role of the employment time in the cross-sectional distribution, is to look at the distribution of earnings growth for workers who have a certain amount of employment time in a given year. In particular we look at the distribution of earnings growth for three groups, and compare them to the full sample for the reference year $(t=1996)$ :

(A) Workers employed for 52 weeks in year $t-1$ (Figure 4 panel (a))

(B) Workers employed for 52 weeks in year $t$ (Figure 4 panel (b))

(C) Workers employed for 52 weeks in both year $t-1$ and year $t$ (Figure 4 panel (c)) 
Figure 4: Log-densities of Earnings Growth in Italy 1996, Group A, B, C
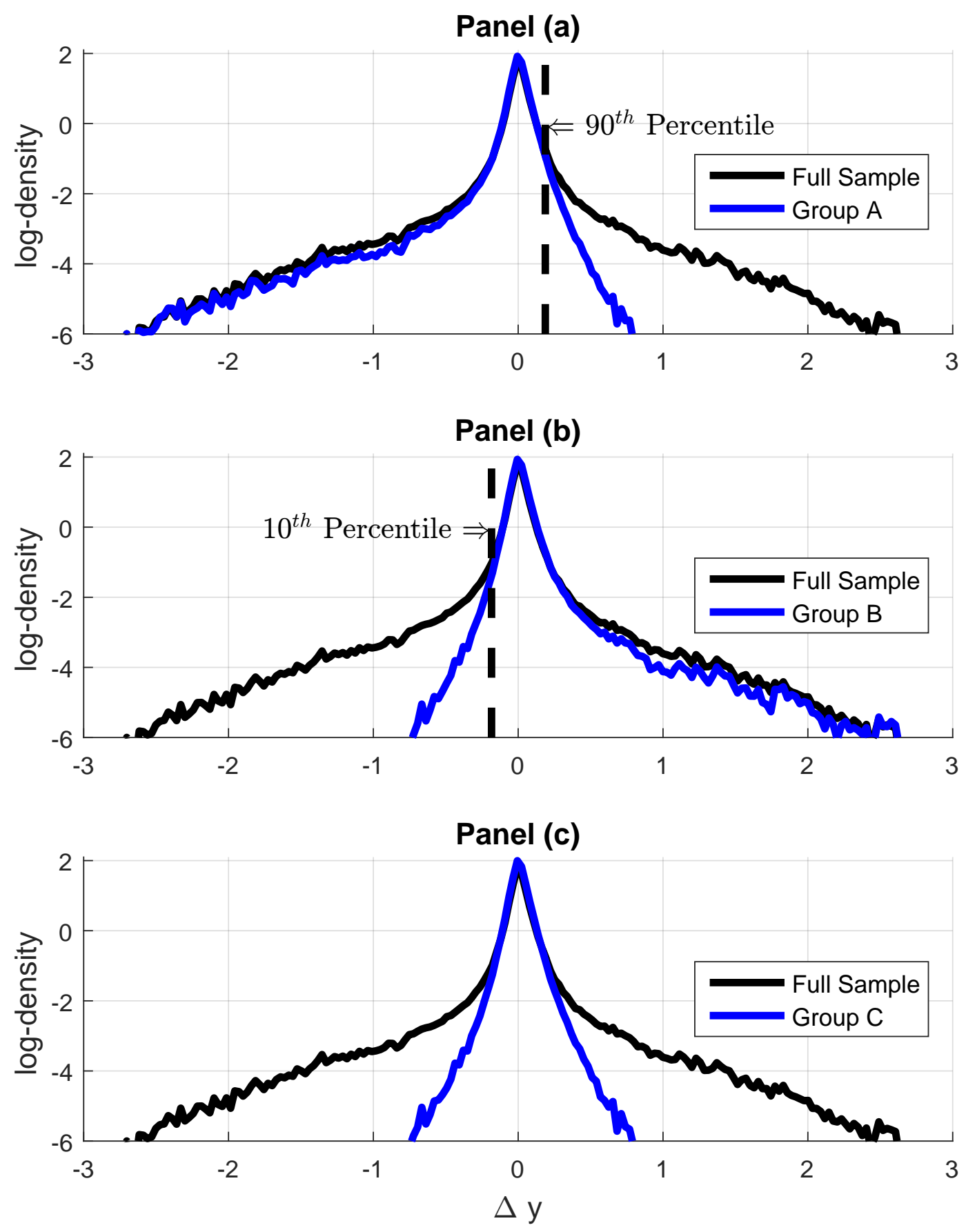

Notes: Black line - full-sample distribution, 25-60 years old males in all panels. Panel (a): blue line, sample restricted to workers who have worked for 52 weeks in year 1995 (group A). Panel (b): blue line, sample restricted to workers who have worked for 52 weeks in year 1996 (group B). Panel (c): blue line, sample restricted to workers who have worked for 52 weeks in both years 1995 and 1996 (group C). Values are log of the kernel density. Source: INPS, see details in text. 
Panel (a) in figure 4 shows the distribution of earnings growth for group A. Since workers in this group were employed for 52 weeks in year $t-1$, their changes in employment time cannot be positive. That is, positive growth in earnings for this group can only be generated by increases in their earnings rate. The right tail of the distribution of group A is considerably thinner than that of the full sample, while retaining the shape and magnitude of the left tail. This implies that the right tail of the distribution is generated almost entirely by workers who are in the complimentary group - those that were employed for less than 52 weeks in year $t-1$. Figure 4 panel (b) is the mirror image of panel (a). Members of group B, who were employed for 52 weeks in year $t$, are unlikely to experience a drop in earnings larger the 10th percentile of the full sample distribution (dashed line). The bottom panel of figure 4 completes the picture. Workers in group C, who were employed for the full 104 weeks of 1995 and 1996, are unlikely to have experienced large positive or negative earnings growth during this period.

To quantify this visual evidence we compare the probability of experiencing large or small earnings growth in each of the groups, and report results in Table 2. Columns (1) and (2) report the 10th and 90th percentile of the full-sample distribution of earnings growth. For each group we compute the probability of experiencing earnings growth below the 10th and above the 90th percentile. The probability of a worker in group A to experience a rise in earnings of greater than the 90th percentile, reported in column (7), is less than 3.2 percent in 1996 (and never above 4.3 percent). Group A includes more than 80 percent of workers in that year, implying that those not working for 52 weeks in year $t-1$, are approximately 12 times more likely to experience large earnings growth. ${ }^{19}$ Similarly, those not employed for 52 weeks in year $t$ (the complimentary group for B) are about 20 times more likely to experience earnings growth lower than the 10th percentile (see Table 2 column (5)).

An additional result in Table 2 is worth mentioning. Both positive and negative large earnings growth events are less likely for groups A, B and C, than for the full-sample. For instance, the probability of a worker in group A to experience earnings growth below the 10th percentile is less than 0.1 in every year. Even though workers in group A can only face a decline in the number of months worked, they face less downward risk than that of workers in the full sample. Similarly workers in group B, can only face an increase in the number of months worked, and yet they face less upward risk than that of workers in the full sample. We conclude that working for 52 weeks in either year $t-1$ or year $t$, is a sign of attachment to the labor market, and thus implies less overall (upward or downward) variations in earnings.

\footnotetext{
${ }^{19}$ By construction, 10 percent of the workers experience a rise in earnings above the 90th percentile. Since $80 \%$ of all workers are in group A, the probability of experiencing earnings growth above the 90th percentile for the complementary group can be found by solving:

$$
0.032 \times 0.8+p \times 0.2=0.1 \Rightarrow p=0.372
$$

so that the workers who are not in group A are $0.372 / 0.035=11.6$ times more likely to experience large earnings growth.
} 
Table 2: Conditional Probabilities of Large Changes in Earnings

\begin{tabular}{|c|c|c|c|c|c|c|c|c|c|}
\hline \multirow[b]{2}{*}{$\begin{array}{c}\text { Year } \\
(1)\end{array}$} & \multicolumn{2}{|c|}{ Percentiles of $\Delta y$} & \multirow[b]{2}{*}{ group: } & \multicolumn{3}{|c|}{$\mathbb{P}($ (drop") } & \multicolumn{3}{|c|}{$\mathbb{P}$ ("jump") } \\
\hline & $\begin{array}{c}\text { P10 } \\
(2)\end{array}$ & $\begin{array}{c}\mathrm{P} 90 \\
(3)\end{array}$ & & $\begin{array}{c}\mathrm{A} \\
(4)\end{array}$ & $\begin{array}{c}\mathrm{B} \\
(5)\end{array}$ & $\begin{array}{c}\mathrm{C} \\
(6)\end{array}$ & $\begin{array}{c}\mathrm{A} \\
(7)\end{array}$ & $\begin{array}{c}\text { B } \\
(8)\end{array}$ & $\begin{array}{c}\mathrm{C} \\
(9)\end{array}$ \\
\hline 1986 & -0.159 & 0.196 & & 0.076 & 0.026 & 0.026 & 0.038 & 0.078 & 0.039 \\
\hline 1987 & -0.134 & 0.228 & & 0.076 & 0.026 & 0.026 & 0.039 & 0.080 & 0.041 \\
\hline 1988 & -0.122 & 0.241 & & 0.080 & 0.031 & 0.031 & 0.034 & 0.079 & 0.035 \\
\hline 1989 & -0.138 & 0.223 & & 0.082 & 0.032 & 0.033 & 0.037 & 0.079 & 0.037 \\
\hline 1990 & -0.143 & 0.214 & & 0.079 & 0.028 & 0.028 & 0.038 & 0.081 & 0.040 \\
\hline 1991 & -0.155 & 0.233 & & 0.076 & 0.021 & 0.021 & 0.037 & 0.082 & 0.039 \\
\hline 1992 & -0.215 & 0.191 & & 0.076 & 0.015 & 0.015 & 0.035 & 0.080 & 0.038 \\
\hline 1993 & -0.272 & 0.141 & & 0.070 & 0.013 & 0.013 & 0.043 & 0.087 & 0.047 \\
\hline 1994 & -0.222 & 0.175 & & 0.074 & 0.016 & 0.016 & 0.032 & 0.080 & 0.034 \\
\hline 1995 & -0.163 & 0.195 & & 0.078 & 0.027 & 0.028 & 0.031 & 0.076 & 0.032 \\
\hline 1996 & -0.179 & 0.187 & & 0.077 & 0.021 & 0.021 & 0.032 & 0.078 & 0.033 \\
\hline 1997 & -0.135 & 0.240 & & 0.075 & 0.023 & 0.023 & 0.035 & 0.078 & 0.037 \\
\hline 1998 & -0.174 & 0.216 & & 0.081 & 0.024 & 0.025 & 0.031 & 0.077 & 0.032 \\
\hline 1999 & -0.157 & 0.244 & & 0.079 & 0.026 & 0.027 & 0.025 & 0.074 & 0.026 \\
\hline 2000 & -0.159 & 0.267 & & 0.078 & 0.028 & 0.028 & 0.021 & 0.075 & 0.022 \\
\hline 2001 & -0.179 & 0.272 & & 0.080 & 0.023 & 0.024 & 0.021 & 0.074 & 0.022 \\
\hline 2002 & -0.184 & 0.245 & & 0.075 & 0.021 & 0.021 & 0.021 & 0.074 & 0.022 \\
\hline 2003 & -0.181 & 0.277 & & 0.076 & 0.020 & 0.021 & 0.014 & 0.067 & 0.014 \\
\hline 2004 & -0.184 & 0.233 & & 0.073 & 0.017 & 0.017 & 0.023 & 0.072 & 0.024 \\
\hline 2005 & -0.228 & 0.214 & & 0.071 & 0.013 & 0.012 & 0.024 & 0.076 & 0.025 \\
\hline 2006 & -0.164 & 0.266 & & 0.076 & 0.019 & 0.019 & 0.017 & 0.069 & 0.018 \\
\hline 2007 & -0.167 & 0.270 & & 0.073 & 0.020 & 0.020 & 0.022 & 0.071 & 0.023 \\
\hline 2008 & -0.201 & 0.249 & & 0.070 & 0.015 & 0.015 & 0.021 & 0.074 & 0.023 \\
\hline 2009 & -0.424 & 0.176 & & 0.070 & 0.004 & 0.004 & 0.032 & 0.086 & 0.036 \\
\hline 2010 & -0.252 & 0.250 & & 0.066 & 0.010 & 0.010 & 0.019 & 0.070 & 0.020 \\
\hline 2011 & -0.246 & 0.228 & & 0.066 & 0.011 & 0.011 & 0.018 & 0.067 & 0.019 \\
\hline 2012 & -0.340 & 0.164 & & 0.063 & 0.007 & 0.007 & 0.027 & 0.073 & 0.029 \\
\hline
\end{tabular}

Notes: conditional probabilities of a large drop (columns 3 to 5 ) or a large jump (columns 6 to 8 ) in annual earnings for selected groups of workers. A drop is defined as a change in annual earnings below the 10th percentile of the unconditional distribution of earnings growth. A jump is defined as a change in annual earnings above the 90th percentile of the unconditional distribution of earnings growth. Group A includes workers who had 52 weeks of employment in year $t-1$, group B includes workers who had 52 weeks of employment in year $t$, group $\mathrm{C}$ includes workers with 52 weeks of employment both in year $t$ and in year $t-1$. Source: INPS, as described in the main text. 
The analysis so far was completely non-parametric, and is invariant to any monotone transformation of earnings growth (90th percentile remains the 90th percentile). However, we are also interested in quantifying the relative magnitudes of the variance of earnings growth associated with employment time and with earnings rate. We conduct a simple variance decomposition of earnings growth measured in logs, into the variance of changes in employment time and changes in earnings rate. We apply this decomposition to the reference year 1996, and get:

$$
\underset{0.141}{\operatorname{var}(\Delta y)}=\underset{0.134}{\operatorname{var}(\Delta x)+2 \operatorname{cov}(\Delta x, \Delta w)+\underset{-0.015}{\operatorname{var}(\Delta w)} 0.021}
$$

where the number below each term is its estimated value.

Equation (11) suggests a large role for changes in employment time (variance of 0.134, implying a standard deviations of 37 percent) compared to only a minor role for changes in earnings rate (variance of 0.021 , implying a standard deviation of 15 percent). One concern in this type of decomposition is that measurement errors in employment time will carry over to earnings rate (also known as "division bias"), and will generate a mechanical negative correlation. However, weeks of work are measured relatively accurately in the INPS data, and we excluded observations with particularly low number of weeks of work, which may lead to large measurement errors. Also, if there was substantial measurement error in employment time, it would have increased the variance of changes in earnings rate, which at 15 percent standard deviation is not likely to be a threat to this measurement exercise. Thus we are confident in the validity of these results, given the choice of $\log$ as the measure of changes.

Table 3 provides values of decomposition (6) for all the years in the sample. Two results for equation (11) and Table 3 are noticeable. First, the variance of changes in employment time is greater than four-fifths of the variance of log earnings growth in all years in the sample. Second, the cross-term, twice the covariance of the two components, is small and negative throughout most of sample period. Together these two results imply that the variance of log earnings growth is mostly driven by changes in employment time rather than changes in earnings rate.

Though it is tempting to claim that changes in employment time make up the bulk of the idiosyncratic risk, we avoid making this claim based on these results. Unemployment spells, though detrimental to annual earnings, may be voluntary and short lived, compared to relatively small, but unanticipated and permanent shocks to wages that have a large impact on welfare. We are however able to conclude so far that the practice of interpreting the variations in annual earnings as wage risk will highly inflate the amount of risk contained in wages, and may lead to incorrect conclusions.

\subsection{Time Series Evidence}

After establishing the role of the employment time in the cross section of earnings growth, we now turn to decomposing the moments of earnings growth. In Figure 5 we present the decompositions of the first three central moments of earnings growth over the sample period. 
Table 3: Variance Decomposition of Earnings Growth, Italy 1986-2012

\begin{tabular}{|c|c|c|c|c|c|c|c|c|}
\hline \multirow{2}{*}{$\begin{array}{l}\text { Year } \\
1986\end{array}$} & \multicolumn{2}{|c|}{$\begin{array}{c}m_{2}(\Delta y) \\
\quad(1)\end{array}$} & \multicolumn{2}{|c|}{$\begin{array}{c}m_{2}(\Delta x) \\
(2)\end{array}$} & \multicolumn{2}{|c|}{$\begin{array}{c}m_{2}(\Delta w) \\
(3)\end{array}$} & \multicolumn{2}{|c|}{$\begin{array}{c}2 m_{1,1}(\Delta x, \Delta w) \\
(4)\end{array}$} \\
\hline & 0.127 & $(0.001)$ & 0.114 & $(0.001)$ & 0.025 & $(0.000)$ & -0.012 & $(0.000)$ \\
\hline 1987 & 0.132 & $(0.001)$ & 0.118 & $(0.001)$ & 0.025 & $(0.000)$ & -0.011 & $(0.000)$ \\
\hline 1988 & 0.132 & $(0.001)$ & 0.119 & $(0.001)$ & 0.025 & $(0.000)$ & -0.011 & $(0.000)$ \\
\hline 1989 & 0.127 & $(0.001)$ & 0.117 & $(0.001)$ & 0.024 & $(0.000)$ & -0.014 & $(0.000)$ \\
\hline 1990 & 0.125 & $(0.001)$ & 0.117 & $(0.001)$ & 0.023 & $(0.000)$ & -0.014 & $(0.000)$ \\
\hline 1991 & 0.138 & $(0.001)$ & 0.129 & $(0.001)$ & 0.024 & $(0.000)$ & -0.015 & $(0.000)$ \\
\hline 1992 & 0.149 & $(0.001)$ & 0.145 & $(0.001)$ & 0.024 & $(0.000)$ & -0.019 & $(0.001)$ \\
\hline 1993 & 0.147 & $(0.001)$ & 0.132 & $(0.001)$ & 0.026 & $(0.000)$ & -0.011 & $(0.000)$ \\
\hline 1994 & 0.150 & $(0.001)$ & 0.140 & $(0.001)$ & 0.025 & $(0.000)$ & -0.016 & $(0.000)$ \\
\hline 1995 & 0.141 & $(0.001)$ & 0.132 & $(0.001)$ & 0.022 & $(0.000)$ & -0.014 & $(0.000)$ \\
\hline 1996 & 0.141 & $(0.001)$ & 0.134 & $(0.001)$ & 0.021 & $(0.000)$ & -0.015 & $(0.000)$ \\
\hline 1997 & 0.143 & $(0.001)$ & 0.137 & $(0.001)$ & 0.022 & $(0.000)$ & -0.016 & $(0.000)$ \\
\hline 1998 & 0.163 & $(0.001)$ & 0.145 & $(0.001)$ & 0.033 & $(0.000)$ & -0.014 & $(0.000)$ \\
\hline 1999 & 0.169 & $(0.001)$ & 0.146 & $(0.001)$ & 0.037 & $(0.001)$ & -0.013 & $(0.001)$ \\
\hline 2000 & 0.174 & $(0.001)$ & 0.154 & $(0.001)$ & 0.033 & $(0.000)$ & -0.014 & $(0.000)$ \\
\hline 2001 & 0.168 & $(0.001)$ & 0.157 & $(0.001)$ & 0.026 & $(0.000)$ & -0.015 & $(0.000)$ \\
\hline 2002 & 0.160 & $(0.001)$ & 0.151 & $(0.001)$ & 0.024 & $(0.000)$ & -0.015 & $(0.000)$ \\
\hline 2003 & 0.166 & $(0.001)$ & 0.160 & $(0.001)$ & 0.024 & $(0.000)$ & -0.018 & $(0.000)$ \\
\hline 2004 & 0.156 & $(0.001)$ & 0.147 & $(0.001)$ & 0.022 & $(0.000)$ & -0.013 & $(0.000)$ \\
\hline 2005 & 0.167 & $(0.001)$ & 0.149 & $(0.001)$ & 0.024 & $(0.000)$ & -0.006 & $(0.000)$ \\
\hline 2006 & 0.165 & $(0.001)$ & 0.148 & $(0.001)$ & 0.023 & $(0.000)$ & -0.006 & $(0.000)$ \\
\hline 2007 & 0.158 & $(0.001)$ & 0.140 & $(0.001)$ & 0.023 & $(0.000)$ & -0.005 & $(0.000)$ \\
\hline 2008 & 0.168 & $(0.001)$ & 0.143 & $(0.001)$ & 0.023 & $(0.000)$ & 0.001 & $(0.000)$ \\
\hline 2009 & 0.202 & $(0.001)$ & 0.168 & $(0.001)$ & 0.028 & $(0.000)$ & 0.006 & $(0.000)$ \\
\hline 2010 & 0.193 & $(0.001)$ & 0.159 & $(0.001)$ & 0.029 & $(0.000)$ & 0.005 & $(0.000)$ \\
\hline 2011 & 0.194 & $(0.001)$ & 0.160 & $(0.001)$ & 0.027 & $(0.000)$ & 0.006 & $(0.000)$ \\
\hline 2012 & 0.197 & $(0.001)$ & 0.167 & $(0.001)$ & 0.028 & $(0.000)$ & 0.002 & $(0.001)$ \\
\hline
\end{tabular}

Notes: the variance of earnings growth (1), is decomposed into the variance of changes in employment time (2), the variance of changes in earnings rate (3) and a cross-term (4). Standard errors are reported in parentheses. Sample includes all 25-60 years old males who appear in the data for two consecutive years. Source: INPS data, see text for full description. 
Figure 5: Moment Decomposition of Earnings Growth, Italy 1986-2012

\section{(a) Mean}

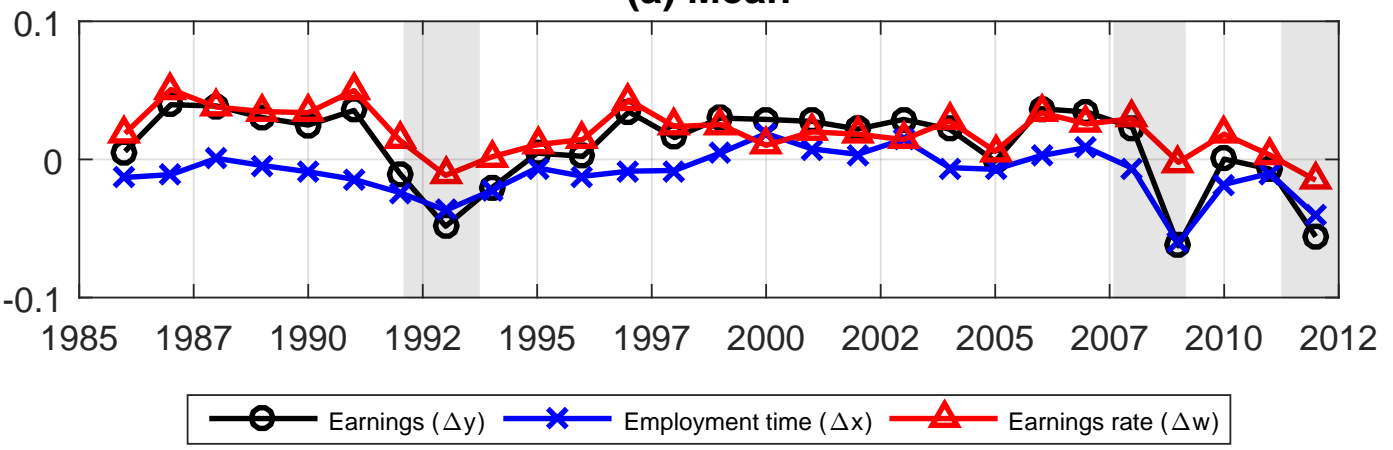

(b) Variance

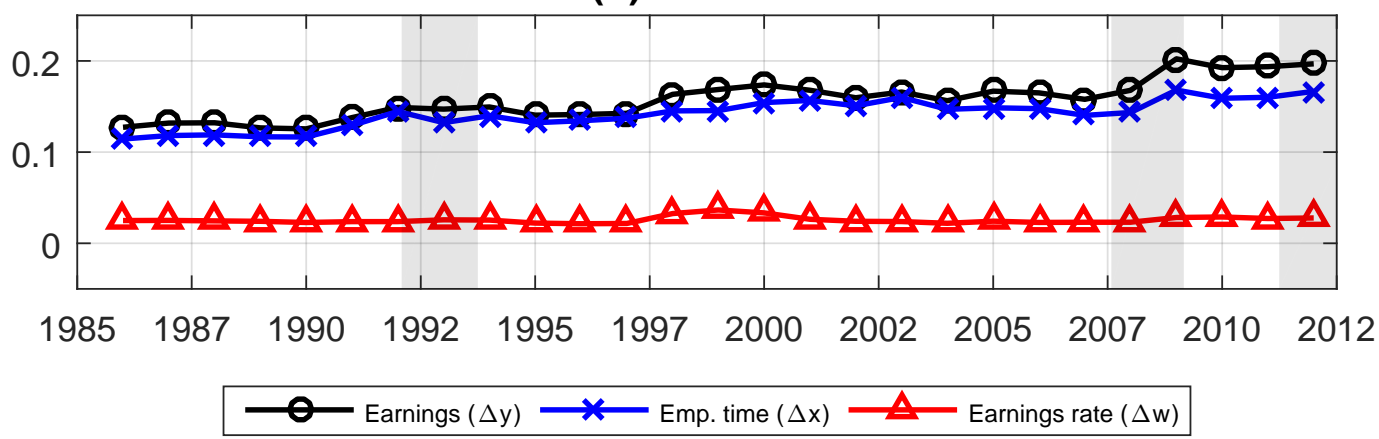

(c) Third Central Moment

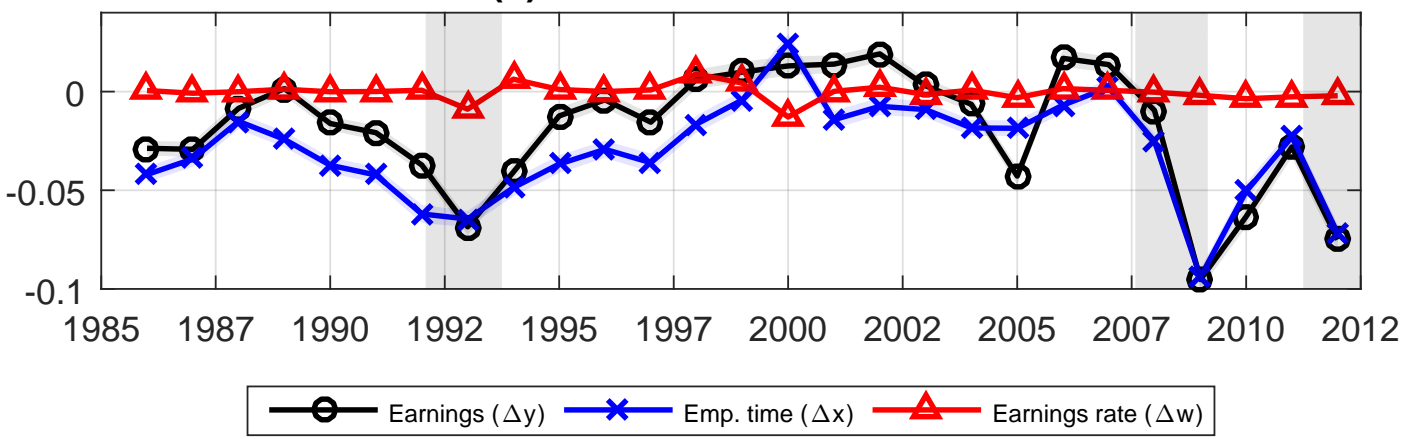

Notes: Panels (a) through (c) present the time series of moments of the cross-sectional distributions. Panel (a) presents decomposition of the mean, panel (b) presents decomposition of the variance and panel (c) presents decomposition of the third central moment. In each panel, there are three lines: annual earnings growth (black), employment time (blue) and earnings rate (red). All variables are measured as difference in logs. The sample includes 25-60 years old males in Italy. Source: INPS, see main text. 
Panel (a) shows the decomposition of the mean. The mean change in employment time remains negative throughout most of the sample period. It reaches a low of -0.07 at 2009 , in the midst of the Great Recession. The mean change in earnings rate is on average a positive 0.02 during expansions. It drops during recessions, reaching a low of -0.02 in 2012 . The dynamic behavior of the means suggests that cyclicality of mean earnings growth reflects cyclical properties of both employment time and earnings rate.

The variance of earnings growth is decomposed in panel (b), visually repeating the variance decomposition reported in Table 3. The variance of earnings growth and the variance of changes employment time follow a long term increasing trend. This trend is particularly evident since the beginning of the Great Recession in 2007. There appears to be some amount of counter cyclicality in the variance earnings growth and changes in employment time, but both seem to be less pronounced than the long term trend. The variance of changes in earnings rate are relatively flat, with a period of higher variance in the late 1990s early 2000s. The variance of changes in employment time seems visually more correlated with the variance of earnings growth.

Panel (c) presents the decomposition of the third central moment. Controlling for the mean and variance, the third central moment captures the asymmetry of the distribution. The third moment of earnings growth and of changes in employment time follow the same path, both in magnitude and in pattern. They are both clearly pro-cyclical, dropping to a negative -0.1 in 2009 , during the Great Recession. The third moment of changes in earnings rate is relatively flat and close to zero. We interpret these results as employment time being the primary source for the observed cyclical asymmetry of earnings growth. We will revisit these results in Section 7 for a more formal quantitative exercise.

\section{Evidence from the US}

In previous sections, we have seen that employment time generates most of the cross-sectional variation in earnings growth and almost all of its asymmetry during recessions. We have yet to explore what is the statistical mechanism that generates these variations. We explore this mechanism in the United States.

Since administrative records of employment time are unavailable for the US, we use a Markov chain statistical model with estimates of labor market flows to recover the implied distributions of changes in employment time, as if those were directly recovered from the data. The model hinges on simplifying assumptions, but it allows us to tractably map aggregate variables, including the job separation rate (the rate at which employed workers become unemployed) and the hiring rate (the rate at which unemployed workers become employed) into cross-sectional distributions of changes in annual employment time, and to compare them to distribution found by GOS. 
As many other studies find, labor market flows are cyclical. In particular, the separation rate increases and the hiring rate decreases during recessions. Using the model, we show how this affects the implied cross-sectional distribution: as the separation rate increases, more employed workers lose their jobs. At the same time, the hiring rate declines, leading to longer unemployment spells, and making large negative changes in employment time more likely. Together they generate skewness in employment time.

We construct time series of the mean, variance and third moment of changes in employment time, and compare them to corresponding time series from GOS. We find that the relationship of the moments of the implied distribution of employment time with the moments from GOS is similar to the relationship we find in Italy, where the actual distributions can be observed. We interpret this as a success of the statistical model to capture important features of the employment time distribution, as well as a sign for the external validity of our findings.

The use of labor market flows derived from survey data, has two additional advantages over administrative data. First, we view monthly frequency as more useful for thinking about cyclicality, as recessions last on average less than a year. The effects of recessions that are shorter than a year might be missed in administrative data, or otherwise confounded with the effects of the recovery (for instance, our model suggests that following a recession there is a period of higher cross-sectional variance). Second, survey data are available in near real time to analysts and policymakers. In particular, the separation rate and the hiring rate, that are found to explain the observed patterns, can be used to adjust policy in response to changes in idiosyncratic risk.

\subsection{Statistical Model}

We describe the model in general lines. A detailed description, including an exact solution and a discussion of the statistical restrictions imposed by the model are available in Appendix C.

In every month $m$, a worker is in one of three employment states: employment $(E)$, unemployment $(U)$, or not-in-labor-force $(N) . P_{i, j}(m)$ is the probability of a worker who is in state $i$ in month $m-1$ to transition to state $j$ in month $m$. This probability is time varying, but common to all workers at time $m$. Together, the transition probabilities form the transition probability matrix $P(m)(3 \times 3$ matrix for each month).

Assuming that conditional on $P(m)$ individual transitions are independent, we can invoke the law of large numbers to recover $P_{i, j}(m)$ from the share of workers that were in state $i$ at month

$m-1$ and are at state $j$ at month $m$, out of all the worker at state $i$ at month $m-1$. We do not allow the transitions to depend on any observed information other than the current state of the worker. This is of course not a realistic assumption, but also one that can be relaxed with the proper data (for instance, one can stratify the sample based on age and education). To keep the model parsimonious, and to avoid dealing with diminishing quality of the data, we retain this assumption in our analysis. 
Annual employment time, denoted by convention using the first month of the year, is the number of months spent in state $E$ out of months $\{m, m+1, \ldots, m+11\}$. Given the share of workers in state $i$ at month $m$, and the probability transition matrices $P(m-12)$ to $P(m+11)$ we can construct the unconditional joint probability of employment time for the year starting at $m-12$ and the year starting at $m$. This joint probability is converted to a probability mass function for changes in log annual employment time between $m-12$ and $m$, conditional on being employed for at least one month in both of the years (corresponding to the empirical definition used with the Italian data). We compute the implied distributions of annual changes in employment time for every month in our sample and use them to construct a time series of the first three moments of the distributions.

\subsection{Transition Rates over the Business Cycle}

We first look at the observed evidence on the cyclicality of transition rates. Other studies, such as Blanchard and Diamond (1989), have looked at transition rates in the context of the aggregate matching functions. Rather than explaining the rates of hiring and separation using other aggregates, we focus on the implications of these transitions on the worker's idiosyncratic changes in employment time. Figure 6 shows the transition rates between labor market states over the sample period, from February 1989 to December 2013.

Several details form Figure 6 are important for our analysis. The diagonal panels (E to E, U to $\mathrm{U}$ and $\mathrm{N}$ to $\mathrm{N}$ ) reveal the persistence of each state. Unemployment is less persistent than both employment and not-in-labor-force states. The transitions from employment to not-in-labor-force and back, that are sometimes neglected in search and matching models, are non-trivial; an employed worker has over 1 percent probability of exiting the labor force, and a worker outside the labor force has about 8 percent probability of becoming employed in the following month. The long-term increasing trend in E-to-N transitions reflects the decrease in the labor force participation among prime working age men (see Hall (2014) for documentation of the trend and a discussion).

The most important detail to our analysis regards the cyclicality of the rate of separation (E to $\mathrm{U}$ ) and the rate of hiring ( $\mathrm{U}$ to $\mathrm{E}$ ). During recessions, the rate of separation (top middle panel) increases and the rate of hiring declines. This is consistent across the three recessions in our sample.

Furthermore, the effect of the recession is slow to wear off, and separation and hiring rates take several years to return to their pre-recession levels, even after relatively mild recessions.

\subsection{Employment Time in Recession and Expansion}

How does the cyclical pattern in the rate of hiring and the rate of separation translate into the cross-sectional distribution of changes in employment time? To illustrate the mechanism we look at the cross-sectional distribution in two periods: 2004-2005 (expansion) and 2008-2009 (recession). 
Figure 6: Labor Market Transition Rates, United States 1989-2013
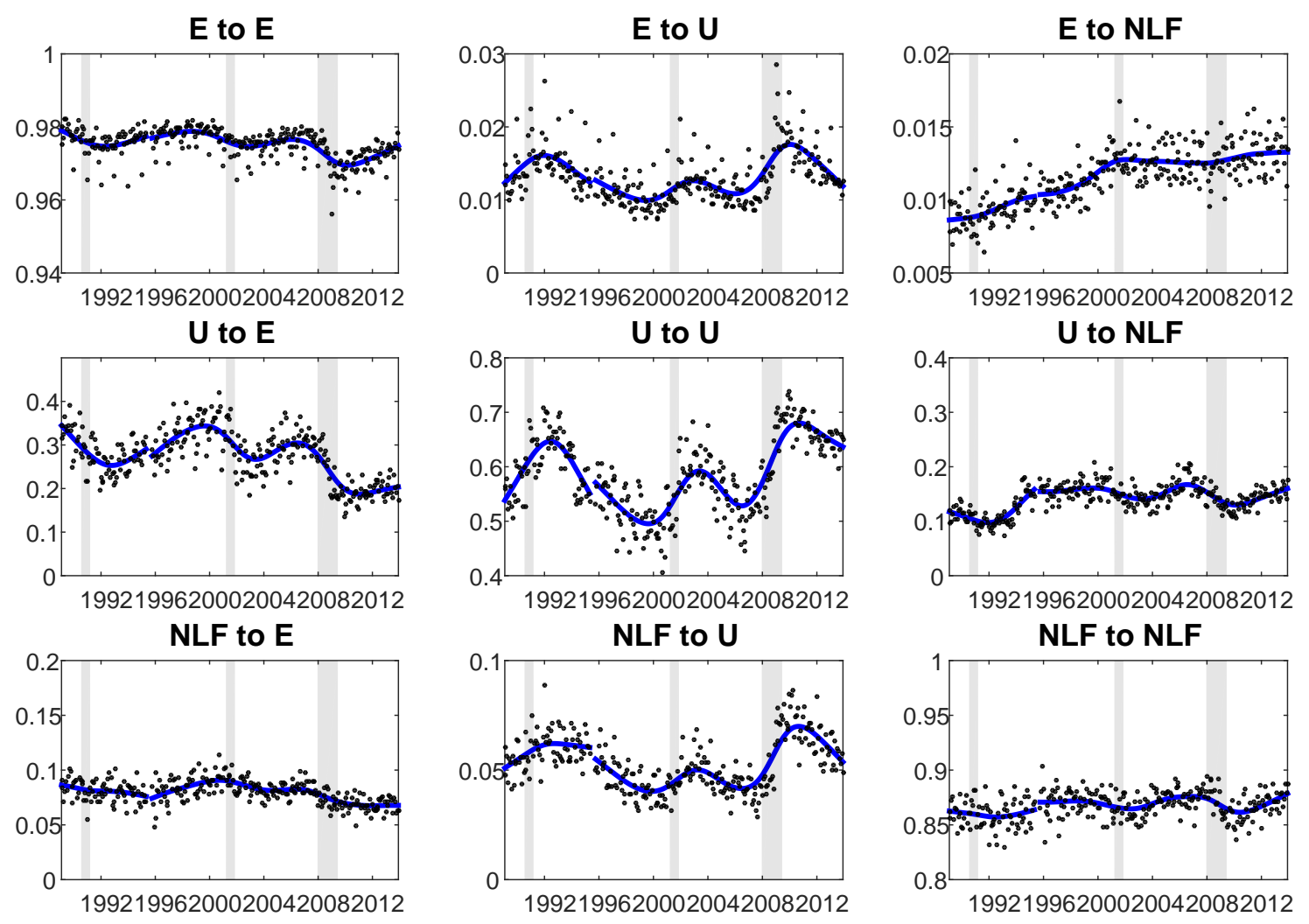

Notes: Labor market states are Employment (E), Unemployment (U) and Not-in-Labor-Force (N). Sample include males 25-60 years old. Dots are monthly point estimates; solid line is HP-filtered time series with parameter 14,400 (monthly). Transition rates between states $i$ and state $j$ are measured as the share of workers that are in state $i$ at month $t-1$ who are at state $j$ at month $t$. All estimates weighted using 'final person weight'. Source: IPUMS-CPS (Flood et al., 2015).

2004 and 2005 were typical expansion years. Only few workers were laid off, and if they were, they found new jobs relatively quickly. Separation rate (E-U) was on average 1.1 percent per month, and the hiring rate (U-E) was on average 28.8 percent per month (implying a mean duration of unemployment of 3.5 months). 2008 and 2009 capture the effect of the Great Recession. The rate of separation reached a peak in January of 2009 - between December 2008 and January 2009 about 2.85 percent of employed men became unemployed. At the same time the hiring rate was rapidly declining, reaching a trough of 13.5 percent in December 2009 (implying a mean duration of 7.4 months), from almost 30 percent in January 2008. 
The cross-sectional distributions of changes in employment time for these two periods are presented in the top panel of Figure 7. Most workers experience little changes in their employment time; the middle column which represents workers who had +/-10 percent change in their employment time includes 64 percent of all workers in the expansion period and 58 percent in the recession period. The median change in both periods is exactly 0 . The rest of the difference between the distribution in expansion and in recession is in the tails of the distributions, as can be seen in the bottom panel of Figure 7 . The difference to the right of the middle column is positive, implying that more workers increase their employment time during expansion than during recession, but relatively small. Most of the difference in the tails is in changes of between negative -0.1 and -1 (which maps into loss of 1 to 8 months of employment).

Figure 7: Employment Time in Recession and Expansion

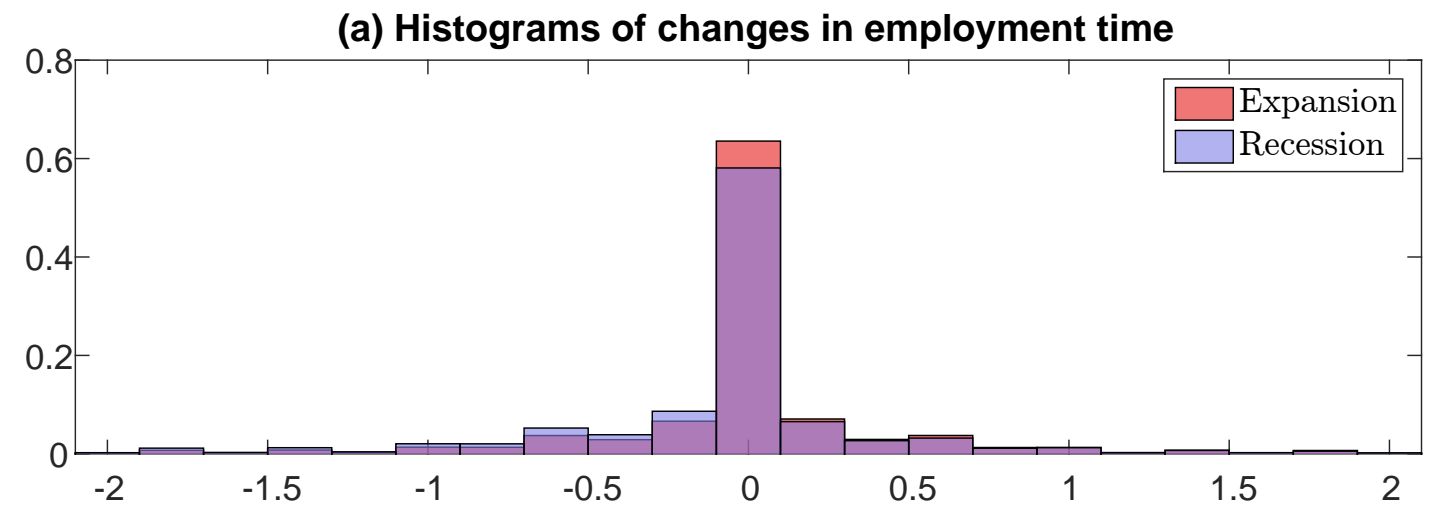

(b) Difference (expansion - recession)

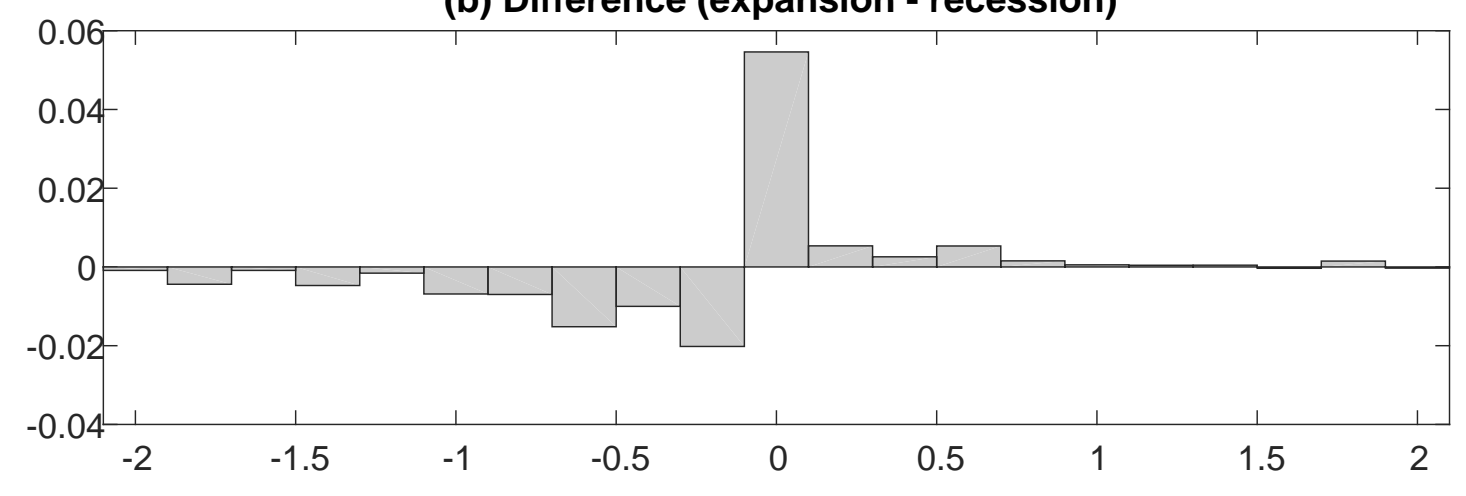

Notes: Panel (a) displays the implied distributions of annual changes in the employment time (difference in logs), measured in expansion (2004-2005, red) and recession (2008-2009, blue). Implied distributions are constructed using CPS flows data and a Markov chain model described in the text. Panel (b) displays the difference between the histograms. The distribution in recession has less probability of small difference $(-0.1$ to +0.1$)$ and higher probability of negative changes (mostly in the range -1.1 to -0.1 ). 
The mean and the third moment of the distribution decline, while the variance increases during recession. The mean declines from -0.1 percent during the expansion period to -8 percent during recession. The decline in the third central moment is driven by two opposing effects. First, large losses of employment time are more common during recessions, pushing down the third moment. Second, due to the decline in the mean, the distance between the mean and large negative outcomes is mechanically shrinking, effectively increasing the third moment. However, the combination of a rise in the separation rate, and a decline in the hiring rate is affecting the distribution asymmetrically, leading to a sharp decline in the third central moment, form -0.01 in 2005 to -0.10 in 2009. In contrast to the third moment, the variance weighs in negative and positive events relative to the mean. Thus as the rate of separation goes up, the unemployment rate goes up, and the unconditional probability of experiencing positive or negative changes increases. The variance of the implied distribution of changes in employment time increases form 0.28 in 2005 to 0.34 in 2009 .

\subsection{Time Series Evidence}

We present the moments of the implied distributions together with the moments of earnings growth provided by Guvenen, Ozkan, and Song (2014) for our sample period in Figure 8. The patterns that we find in the implied distributions are similar to the ones we find in the administrative data for Italy (absent the observation of the earnings rate).

The model is successful in generating the mean effect, as seen in panel (a). The mean change in employment time closely follows the pattern of the mean earnings growth, and is never positive. The variance of changes in employment time, presented in panel (b), exhibits an upward trend, similar to the one observed in Italy, but surprisingly at odds with a downward trend in the variance of earnings growth provided by GOS. The long term trend is explained by an increase in the share of worker who are not-in-the-labor force at any given time, and so may experience large adjustments in employment time. The third central moment of changes in employment time, presented in panel (c) closely follows the third moment of earnings rate, replicating the most striking evidence from Italy. We conclude that as in Italy, employment time is also the primary source of asymmetry in the cross-section of earnings growth during recessions. 
Figure 8: Moments Decomposition of Earnings Growth, US 1989-2013

\section{(a) Mean}

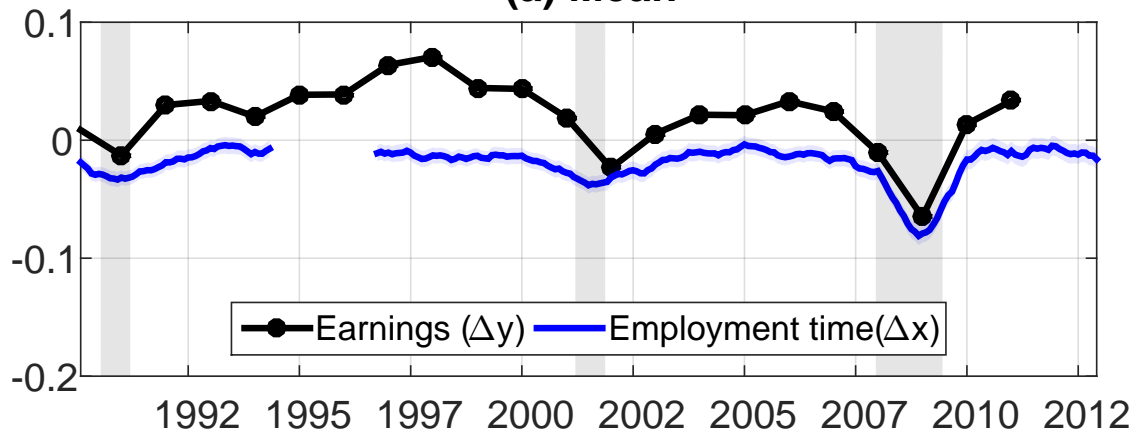

(b) Variance

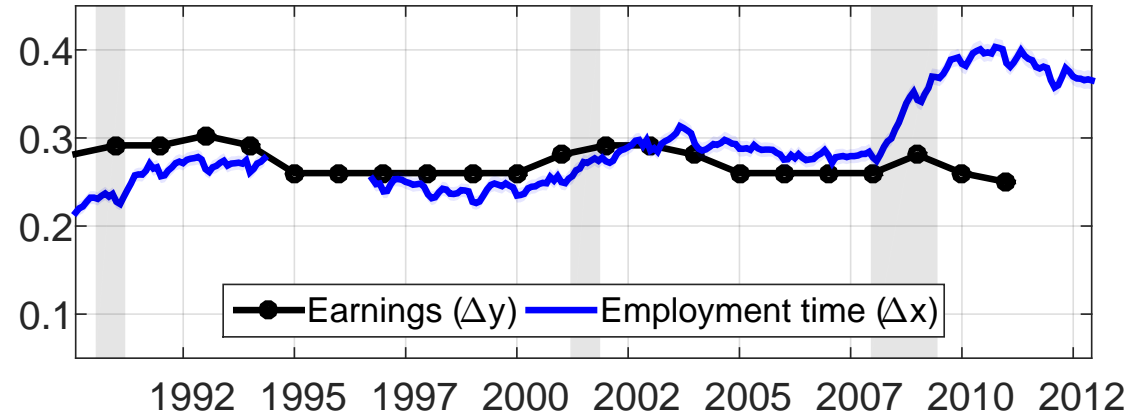

(c) Third central moment

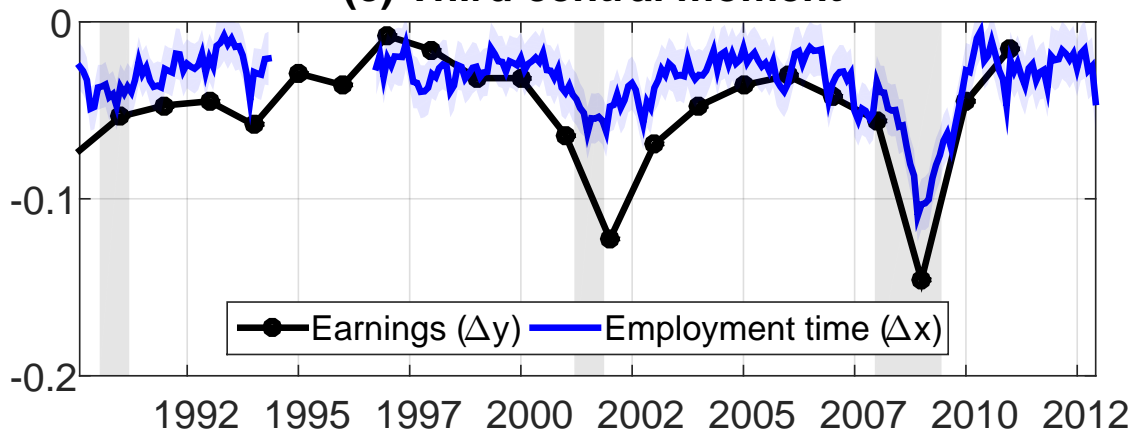

Notes: Moments of of earnings growth $\Delta y$ (black) and moments of the implied distribution of changes in employment time $\Delta x$ (blue). Construction of implied distributions described in text. Panel (a) shows the mean of the distributions, panel (b) shows the variance of the distributions and panel (c) shows the third central moment of the distributions, defined as $\mathbb{E}_{i}\left[\left(z_{i t}-\mathbb{E}\left(z_{i t}\right)\right)^{3}\right]$ for any variable $z_{i t}$ at every time $t$. Shaded area around moments of changes in employment time are 0.95 confidence intervals computed using 500 bootstrap replications. Sources: Guvenen, Ozkan, and Song (2014) and IPUMS-CPS (Flood et al., 2015). 


\section{Accounting for Cyclicality}

In this section we complement the visual evidence in the previous two sections with a quantitative exercise. We define the cyclicality of each moment of earnings growth as its correlation with GDP growth (after removal of trend). We apply this definition to the constructed time series from Italy and the US, and check whether changes in employment growth can account for the cyclical pattern of earnings growth. If controlling for moments of changes in employment time eliminates the correlation between moments of earnings growth and GDP growth, we conclude that changes in employment time account for the cyclicality of earnings growth. Consistent with the visual evidence in Figures 5 and 8, we find that changes in employment time can account for the cyclicality of the third moment of earnings growth, both in Italy and in the United States, suggesting that changes in employment time are generating the distribution of earnings growth.

\subsection{Quantitative Exercise}

We perform regression analysis to determine whether changes in employment time capture the cyclical patterns of moments of employment growth. Consider the detrended and standardized time series of moments of earnings growth $\Delta y$, changes in employment time $\Delta x$ and GDP growth $\hat{g}_{t}$. Denote $\hat{m}_{t}^{n}(\cdot)$ as the detrended and standardized $n$th moment of the cross-sectional distribution at year $t$. The unconditional correlation between $\hat{m}_{t}^{n}\left(\Delta y_{i t}\right)$ and $\hat{g}_{t}$ is estimated as the coefficient $\beta_{n}$ in the following regression:

$$
\hat{m}_{t}^{n}\left(\Delta y_{i t}\right)=\beta_{n} \hat{g}_{t}+\epsilon_{t}
$$

The controlled coefficient $\beta_{n x}$ is estimated in the following regression:

$$
\hat{m}_{t}^{n}\left(\Delta y_{i t}\right)=\beta_{n x} \hat{g}_{t}+\gamma_{n x} \hat{m}_{t}^{n}\left(\Delta x_{i t}\right)+\epsilon_{t}^{x}
$$

In case that the $n$th moment is correlated with GDP growth (that is, $\beta_{n} \neq 0$ ), we check whether controlling for employment time in equation (13) eliminates the correlation (that is, $\beta_{n x}=0$ ). If it does, we interpret that as employment time accounting for the cyclicality of that moment.

\subsection{Results}

We report the results for the mean, variance, third moment and skewness of earnings growth for Italy and the US in Table 4. 
Table 4: Accounting for Cyclicality of Earnings Growth - Employment Time

(A) Dependent Variable: Third Moment of $\Delta y$

\begin{tabular}{lrrrrr}
\hline & \multicolumn{2}{c}{ Italy } & & \multicolumn{2}{c}{ US } \\
\cline { 2 - 3 } \cline { 5 - 6 } & $(1)$ & $(2)$ & & $(3)$ & $(4)$ \\
\hline GDP Growth & $\mathbf{0 . 6 3 9}$ & -0.122 & & $\mathbf{0 . 6 6 8}$ & 0.088 \\
& $(0.154)$ & $(0.133)$ & & $(0.181)$ & $(0.197)$ \\
Third Moment of $\Delta x$ & & $\mathbf{0 . 9 9 6}$ & & $\mathbf{0 . 7 8 2}$ \\
& & $(0.133)$ & & $(0.197)$ \\
\hline R-squared & 0.41 & 0.82 & & 0.45 & 0.72 \\
Observations & 27 & 27 & & 19 & 19 \\
\hline
\end{tabular}

(B) Dependent Variable: Skewness of $\Delta y$

\begin{tabular}{lrrrrr}
\hline & \multicolumn{2}{c}{ Italy } & & \multicolumn{2}{c}{ US } \\
\cline { 2 - 3 } \cline { 5 - 6 } & \multicolumn{1}{c}{$(1)$} & $(2)$ & & $(3)$ & $(4)$ \\
\hline GDP Growth & $\mathbf{0 . 6 0 6}$ & -0.096 & & $\mathbf{0 . 6 7 9}$ & 0.215 \\
& $(0.159)$ & $(0.138)$ & & $(0.178)$ & $(0.210)$ \\
Skewness of $\Delta x$ & & $\mathbf{0 . 9 5 7}$ & & $\mathbf{0 . 6 4 4}$ \\
& & $(0.138)$ & & $(0.210)$ \\
\hline R-squared & 0.37 & 0.79 & & 0.46 & 0.66 \\
Observations & 27 & 27 & & 19 & 19 \\
\hline
\end{tabular}

(C) Dependent Variable: Mean of $\Delta y$

\begin{tabular}{lrrrrr}
\hline & \multicolumn{2}{c}{ Italy } & & \multicolumn{2}{c}{ US } \\
\cline { 2 - 3 } \cline { 5 - 6 } & $(1)$ & $(2)$ & & $(3)$ & $(4)$ \\
\hline GDP Growth & $\mathbf{0 . 7 1 6}$ & 0.066 & & $\mathbf{0 . 8 3 3}$ & $\mathbf{0 . 5 0 3}$ \\
& $(0.140)$ & $(0.159)$ & & $(0.134)$ & $(0.223)$ \\
Mean of $\Delta x$ & & $\mathbf{0 . 8 2 5}$ & & 0.400 \\
& & $(0.159)$ & & $0.223)$ \\
\hline R-squared & 0.51 & 0.77 & & 0.69 & 0.74 \\
Observations & 27 & 27 & & 19 & 19 \\
\hline
\end{tabular}

(D) Dependent Variable: Variance of $\Delta y$

\begin{tabular}{lrrrrr}
\hline & \multicolumn{2}{c}{ Italy } & & \multicolumn{2}{c}{ US } \\
\cline { 2 - 3 } \cline { 5 - 6 } & $(1)$ & $(2)$ & & $(3)$ & $(4)$ \\
\hline GDP Growth & -0.327 & -0.152 & & $\mathbf{- 0 . 5 0 6}$ & $\mathbf{- 0 . 4 5 5}$ \\
Variance of $\Delta x$ & $(0.189)$ & $(0.143)$ & & $(0.209)$ & $(0.203)$ \\
& & $\mathbf{0 . 6 8 0}$ & & 0.325 \\
R-squared & & $(0.143)$ & & $0.203)$ \\
Observations & 0.11 & 0.54 & & 0.26 & 0.36 \\
\hline
\end{tabular}

Notes: The dependent variables are moments of earnings growth $\left(\Delta y_{i t}\right)$ reported in the title of each panel. Standard errors are reported in parentheses. Coefficients in bold are significant at the 5 percent level. The control variables are GDP growth and the moment of changes in employment 3 îme. All the time series are detrended and standardized. 
Panel A displays the results for the third moment of the distribution, which captures the asymmetry of the distribution. The correlation between the third moment of earnings growth and GDP growth in Italy is 0.639 (column 1), but drops to insignificant -0.112 (column 2) after controlling for the third moment of changes in employment time. The same thing happens with the correlations in the US: the correlation falls from 0.668 (column 3) to 0.088 (column 4). We interpret this result as implying that the cyclicality of the third moment of earnings growth can be accounted for by changes in employment time. This result complements the visual evidence in Figures 5 and 8. We check the robustness of the result by using skewness instead of the third moment in panel B. Skewness, the standardized third moment, is another measure of asymmetry. We find that the regressions for skewness display the same qualitative results.

Panels $\mathrm{C}$ displays the results for the mean of earnings growth. In Italy and the US the mean earnings growth is highly correlated with GDP growth (panel C columns 1 and 3, 0.716 and 0.833 respectively). In Italy, when controlling for employment time, the the correlation drops to 0.066 and becomes insignificant. In the US however, the correlation remains significant at 0.503 (column 4 , $\mathrm{p}$-value $=0.03$ ). This difference could be driven a more frictional labor market in Italy than in the US, which causes wages to adjust more slowly to the business cycle.

Panels D displays the results for the variance of earnings growth. In both Italy and the US the variance is negatively correlated with GDP growth (columns 1 and 3, -0.327 and -0.506 respectively), though it is only significant in the US. When controlling for employment time the coefficients on GDP growth do not change much. In the US, the coefficient on employment time is not significant (column 4). Looking at Figure 8 suggests that the variance of employment time is cyclical, but at a lag: the variance of changes in employment tends to rise right after recessions. ${ }^{20}$ This lagged pattern is not apparent in Figure 5. In Italy, the coefficient on employment time is large and significant (column 2).

\subsection{Discussion}

The method we use is simple, and may raise several concerns. The first regards the definition of cyclicality. Other studies that quantify cyclicality often use correlation to a measure of the cycle, such as deterended GDP or unemployment, rather than GDP growth. Since we measure the cyclicality of earnings growth, a first difference in itself, we believe the corresponding measure of the cycle should also be a first difference. We also detrend the time series, but only to avoid reporting correlations coming from long term trends (and with little effect on our results).

A second objection, is that cyclical patterns can appear as lagged correlations of variables, and not only contemporaneous movements. Focusing exclusively on contemporaneous correlation may limit our ability to capture the cyclical patterns. Since our time series are in annual frequency, a fine analysis of the business cycle, which is usually done in quarterly frequency, cannot be conducted, and thus we defer this effort to future research.

\footnotetext{
${ }^{20}$ Recall that as the share of unemployed workers goes up the variance of employment time goes up. Unemployment usually peaks at the vary end of a recession, and might stay high for a long time, as in the Great Recession.
} 
Lastly, if controlling for employment time eliminates the correlation of a moment of earnings growth with GDP growth, it does not rule out earnings rate also accounting for the cyclicality. For instance, if the moments of earnings growth, changes in employment time and changes in earnings rate all follow a common pattern, we would mistakenly conclude employment time accounts for the cyclicality when it is actually both components that account for it. This is not the case here. A visual investigation of the evidence from Italy suggests that earnings rate plays only a minor role in generating the second and third moment of earnings growth. We perform a robustness check to verify this result, by replacing employment time with earnings rate, and find that earnings rate cannot account for the cyclicality. Those results are presented in Appendix D.

\section{Conclusions}

In this paper we show that earnings growth is driven by two components - employment time and earnings rate - with different statistical properties and different implications. Out of the two components, employment time is the primary source of tail events (growth lower than the 10th or higher than the 90th percentile). Measured in logs, employment time is responsible for more than four-fifths of the cross-sectional variance of earnings growth, and is the dominant source of cyclicality in earnings growth documented by Guvenen, Ozkan, and Song (2014). Compared to employment time, the earnings rate has stable cross-sectional moments and a third moment that is close to zero.

In many economic applications, focusing on log earnings growth, without addressing the distinction between employment time and earnings rate may be misleading. A statistical model for the individual employment process, along the lines of the statistical model used in this study, can more realistically capture the type of risks associated with employment. Interactions between the employment process and the earnings rate process, found in micro-level data, may be important for macro-economic and policy models (see for example Davis and von Wachter (2011), and Saporta-Eksten (2014)).

Employment risk itself is highly counter cyclical. Policies adjusting unemployment insurance benefits according to aggregate conditions, such as the ones suggested by Landais, Michaillat, and Saez (2010), Kroft and Notowidigdo (2011) and Schmieder, von Wachter, and Bender (2012), have the potential to substantially reduce idiosyncratic risk. In our simple model, we show that a rising separation rate, and a falling hiring rate explain the cyclical asymmetry of earnings growth during recessions. The separation rate and the hiring rate are both collected in surveys in near real time. Therefore, policies that rely on these indicators as determinants of benefits should be further explored. 


\section{References}

Abowd, J. and D. Card (1989). On the Covariance Structure of Earnings and Hours Changes. Econometrica 57(2), 411-45.

Abowd, J. M. and A. Zellner (1985). Estimating gross labor-force flows. Journal of Business 86 Economic Statistics 3(3), 254-283.

Blanchard, O. J. and P. Diamond (1989). The beveridge curve. Brookings Papers on Economic Activity 20(1), 1-76.

Blundell, R., A. Bozio, and G. Laroque (2011). Labor supply and the extensive margin. The American Economic Review 101 (3), 482-486.

Brav, A., G. M. Constantinides, and C. C. Geczy (2002, August). Asset Pricing with Heterogeneous Consumers and Limited Participation: Empirical Evidence. Journal of Political Economy 110(4), 793-824.

Chetty, R. (2012). Bounds on elasticities with optimization frictions: A synthesis of micro and macro evidence on labor supply. Econometrica 80(3), 969-1018.

Constantinides, G. M. and D. Duffie (1996). Asset pricing with heterogeneous consumers. Journal of Political economy, 219-240.

Constantinides, G. M. and A. Ghosh (2014, May). Asset pricing with countercyclical household consumption risk. Working Paper 20110, National Bureau of Economic Research.

Davis, S. J., R. J. Faberman, and J. Haltiwanger (2012). Labor market flows in the cross section and over time. Journal of Monetary Economics 59(1), 1-18.

Davis, S. J. and T. M. von Wachter (2011). Recessions and the cost of job loss. Technical report, National Bureau of Economic Research.

Flood, S., M. King, S. Ruggles, and J. R. Warren (2015). Current Population Survey: Version 4.0. [Machine-readable database].

French, E. and J. Song (2014). The effect of disability insurance receipt on labor supply. American Economic Journal: Economic Policy 6(2), 291-337.

Golosov, M., M. Troshkin, and A. Tsyvinski (2013). Redistribution and social insurance. NBER Working Paper 17642.

Guvenen, F. (2009). An empirical investigation of labor income processes. Review of Economic Dynamics 12(1), 58-79.

Guvenen, F., F. Karahan, S. Ozkan, and J. Song (2015, January). What Do Data on Millions of U.S. Workers Reveal about Life-Cycle Earnings Risk? NBER Working Papers 20913, National Bureau of Economic Research, Inc. 
Guvenen, F., S. Ozkan, and J. Song (2014). The nature of countercyclical income risk. Journal of Political Economy 122(3), 621-660.

Hall, R. E. (2014). Quantifying the lasting harm to the us economy from the financial crisis. In NBER Macroeconomics Annual 2014, Volume 29. University of Chicago Press.

Hansen, G. D. (1985). Indivisible labor and the business cycle. Journal of monetary Economics 16(3), 309-327.

Heckman, J. J. and G. J. Borjas (1980). Does unemployment cause future unemployment? definitions, questions and answers from a continuous time model of heterogeneity and state dependence. Economica, 247-283.

Kiefer, N. M. (1988). Economic duration data and hazard functions. Journal of economic literature, 646-679.

Kocherlakota, N. and L. Pistaferri $(2009,06)$. Asset Pricing Implications of Pareto Optimality with Private Information. Journal of Political Economy 117(3), 555-590.

Kopczuk, W., E. Saez, and J. Song (2010). Earnings inequality and mobility in the united states: evidence from social security data since 1937. The Quarterly Journal of Economics 125(1), $91-128$.

Kroft, K. and M. J. Notowidigdo (2011, June). Should unemployment insurance vary with the unemployment rate? theory and evidence. Working Paper 17173, National Bureau of Economic Research.

Krusell, P. and A. A. Smith (1997). Income and wealth heterogeneity, portfolio choice, and equilibrium asset returns. Macroeconomic dynamics 1(02), 387-422.

LaLonde, R. J. (2007). The case for wage insurance.

Landais, C., P. Michaillat, and E. Saez (2010, November). A macroeconomic theory of optimal unemployment insurance. Working Paper 16526, National Bureau of Economic Research.

Low, H., C. Meghir, and L. Pistaferri (2010). Wage risk and employment risk over the life cycle. American Economic Review $100(4), 1432-67$.

MaCurdy, T. E. (1982). The use of time series processes to model the error structure of earnings in a longitudinal data analysis. Journal of Econometrics 18(1), 83-114.

Mankiw, N. (1986). The equity premium and the concentration of aggregate shocks. Journal of Financial Economics 17(1), 211 - 219.

Meghir, C. and L. Pistaferri (2004). Income Variance Dynamics and Heterogeneity. Econometrica 72(1), 1-32. 
Meyer, B. D. (1990). Unemployment insurance and unemployment spells. Econometrica 58(4), $757-782$.

Rogerson, R. (1988). Indivisible labor, lotteries and equilibrium. Journal of monetary Economics 21(1), 3-16.

Saporta-Eksten, I. (2014). Job loss, consumption and unemployment insurance. Unpublished manuscript.

Schmidt, L. (2016). Climbing and falling off the ladder: Asset pricing implications of labor market event risk.

Schmieder, J. F., T. von Wachter, and S. Bender (2012). The effects of extended unemployment insurance over the business cycle: Evidence from regression discontinuity estimates over 20 years. The Quarterly Journal of Economics 127(2), 701-752.

Sericola, B. (2000). Occupation times in markov processes. Communications in Statistics. Stochastic Models 16(5), 479-510.

Shimer, R. (2012). Reassessing the ins and outs of unemployment. Review of Economic Dynamics $15(2), 127-148$.

Song, J. G. and J. Manchester (2007). New evidence on earnings and benefit claims following changes in the retirement earnings test in 2000. Journal of Public Economics 91(3), 669-700.

Storesletten, K., C. I. Telmer, and A. Yaron (2004a). Consumption and risk sharing over the life cycle. Journal of monetary Economics 51(3), 609-633.

Storesletten, K., C. I. Telmer, and A. Yaron (2004b). Cyclical dynamics in idiosyncratic labor market risk. Journal of Political Economy 112(3), 695-717.

Storesletten, K., C. I. Telmer, and A. Yaron (2007). Asset pricing with idiosyncratic risk and overlapping generations. Review of Economic Dynamics 10(4), 519-548.

von Wachter, T., J. G. Song, and J. Manchester (2011). Trends in employment and earnings of allowed and rejected applicants to the social security disability insurance program. The American Economic Review 101(7), 3308-3329. 


\section{A Data Appendix}

In Table A.1 we report summary statistics for the years 1992, 2002 and 2012 of the sample. Similar statistics for all the years in our sample are available from the authors upon request. In Table A.2 we report mean, standard deviation, 10th, 50th and 90th percentile of the main variables of interest (annual and monthly earnings growth as well as employment time growth) in all years of our sample. Table A.3 reports summary statistics from the monthly matched CPS sample.

\section{A.1 Top Codes}

The INPS data is top coded at a rate based on daily earnings for each job. In 2012, the income is top coded at $€ 645$ per day. In previous years the maximum value is obtained from the occupation specific index on pre-tax retribution provided by ISTAT (the Italian Statistical Institute) available here. At each year, approximately 0.5 percent of the worker-year observations are affected by top coding. Removal of those observations does not affect our results. We have also checked our

analysis on a smaller non top-coded data set (4 birth dates per year) kindly provided to us by the researchers at Bocconi University. The same patterns described in the paper using the top-coded data remain.

\section{A.2 Additional Information}

Additional information about the INPS data can be found on the website of the Italian Ministry of Labor. Additional information about IPUMS-CPS is available at cps.ipums.org 
Table A.1: Summary Statistics for Selected Years

\begin{tabular}{lcrrrrr} 
& \multicolumn{5}{c}{ Year 1992 } \\
\cline { 2 - 6 } & Obs & Mean & Std.Dev. & P10 & P50 & P90 \\
\hline Age & 339,296 & 40.62 & 9.42 & 28.00 & 40.00 & 54.00 \\
Annual Earnings & 339,296 & $29,116.23$ & $19,357.03$ & $12,969.15$ & $24,977.62$ & $47,073.21$ \\
Employment Time (Weeks) & 339,296 & 48.10 & 9.78 & 36.00 & 52.00 & 52.00 \\
Earnings Rate (Weekly Earnings) & 339,296 & 598.15 & 369.45 & 334.78 & 498.81 & 929.89 \\
\hline$\Delta$ Earnings $(\Delta y)$ & 339,296 & -0.01 & 0.39 & -0.22 & 0.00 & 0.19 \\
$\Delta$ Employment Time $(\Delta x)$ & 339,296 & -0.02 & 0.38 & -0.14 & 0.00 & 0.06 \\
$\Delta$ Earnings Rate $(\Delta w)$ & 339,296 & 0.01 & 0.16 & -0.10 & 0.01 & 0.14
\end{tabular}

Year 2002

\begin{tabular}{lcrrrrr}
\cline { 2 - 6 } & Obs & Mean & Std.Dev. & P10 & P50 & P90 \\
\hline Age & 347,323 & 39.99 & 8.85 & 29.00 & 39.00 & 53.00 \\
Annual Earnings & 347,323 & $27,841.43$ & $19,277.20$ & $12,117.09$ & $23,410.70$ & $45,880.26$ \\
Employment Time (Weeks) & 347,323 & 48.33 & 9.54 & 37.00 & 52.00 & 52.00 \\
Earnings Rate (Weekly Earnings) & 347,323 & 568.56 & 367.79 & 316.73 & 464.68 & 902.67 \\
\hline$\Delta$ Earnings $(\Delta y)$ & 347,323 & 0.02 & 0.40 & -0.18 & 0.01 & 0.25 \\
$\Delta$ Employment Time $(\Delta x)$ & 347,323 & 0.00 & 0.39 & -0.08 & 0.00 & 0.12 \\
$\Delta$ Earnings Rate $(\Delta w)$ & 347,323 & 0.02 & 0.16 & -0.10 & 0.01 & 0.15
\end{tabular}

Year 2012

\begin{tabular}{lcrrrrr}
\cline { 2 - 6 } & Obs & Mean & Std.Dev. & P10 & P50 & P90 \\
\hline Age & 374,901 & 42.41 & 8.83 & 30.00 & 42.00 & 55.00 \\
Annual Earnings & 374,901 & $27,218.92$ & $19,088.43$ & $9,914.40$ & $23,416.86$ & $45,795.07$ \\
Employment Time (Weeks) & 374,901 & 46.98 & 11.21 & 29.00 & 52.00 & 52.00 \\
Earnings Rate (Weekly Earnings) & 374,901 & 563.79 & 355.65 & 312.32 & 468.48 & 899.84 \\
\hline$\Delta$ Earnings $(\Delta y)$ & 374,901 & -0.05 & 0.45 & -0.34 & -0.02 & 0.17 \\
$\Delta$ Employment Time $(\Delta x)$ & 374,901 & -0.04 & 0.41 & -0.24 & 0.00 & 0.06 \\
$\Delta$ Earnings Rate $(\Delta w)$ & 374,901 & -0.02 & 0.17 & -0.15 & -0.01 & 0.12
\end{tabular}

Sources: INPS data (as described in the main text). The sample is restricted to males 25-60 years old who ever had a record at the Italian social security administration between 1984 and 2012. Earnings data are in 2013 euros. 


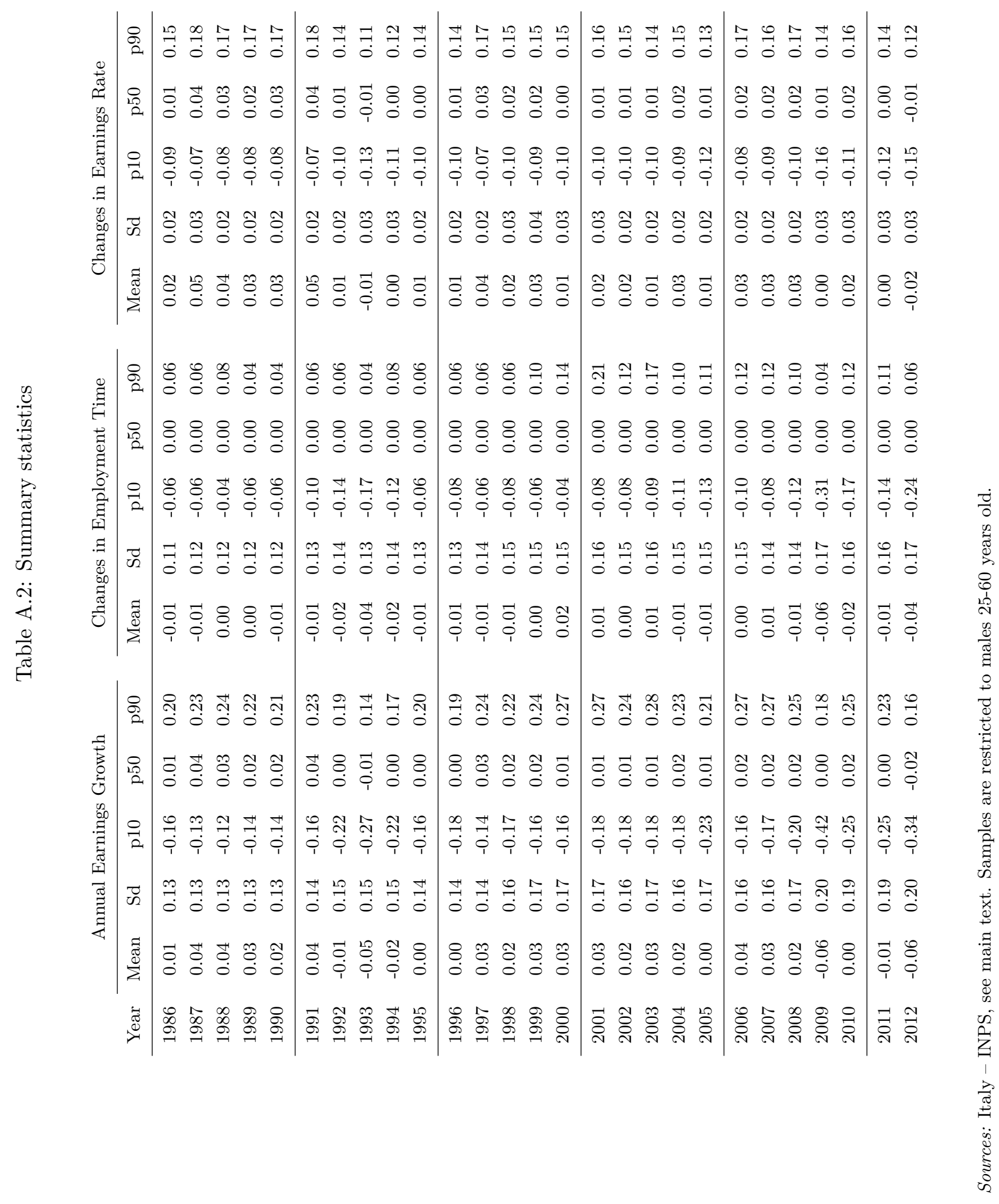


Table A.3: Summary Statistics - January Matched CPS

\begin{tabular}{|c|c|c|c|c|c|}
\hline \multirow[t]{2}{*}{ Year } & \multirow[t]{2}{*}{ Observations } & \multirow[t]{2}{*}{ Age } & \multicolumn{3}{|c|}{ Employment State } \\
\hline & & & $\mathrm{E}$ & $\mathrm{U}$ & $\mathrm{N}$ \\
\hline 1989 & 21,713 & 39.8 & 0.878 & 0.043 & 0.079 \\
\hline 1990 & 23,103 & 39.8 & 0.873 & 0.045 & 0.082 \\
\hline 1991 & 23,253 & 39.9 & 0.858 & 0.055 & 0.086 \\
\hline 1992 & 23,303 & 40.0 & 0.843 & 0.070 & 0.087 \\
\hline 1993 & 22,902 & 40.2 & 0.846 & 0.064 & 0.090 \\
\hline 1994 & 22,757 & 40.2 & 0.847 & 0.058 & 0.096 \\
\hline 1995 & 23,008 & 40.4 & 0.858 & 0.046 & 0.095 \\
\hline 1996 & 19,667 & 40.6 & 0.854 & 0.046 & 0.100 \\
\hline 1997 & 20,208 & 40.7 & 0.858 & 0.043 & 0.098 \\
\hline 1998 & 20,508 & 41.0 & 0.866 & 0.037 & 0.097 \\
\hline 1999 & 20,498 & 41.2 & 0.873 & 0.032 & 0.096 \\
\hline 2000 & 20,870 & 41.4 & 0.873 & 0.030 & 0.096 \\
\hline 2001 & 20,064 & 41.6 & 0.866 & 0.034 & 0.100 \\
\hline 2002 & 24,008 & 41.8 & 0.842 & 0.052 & 0.106 \\
\hline 2003 & 24,181 & 41.9 & 0.833 & 0.053 & 0.114 \\
\hline 2004 & 23,576 & 42.0 & 0.841 & 0.049 & 0.111 \\
\hline 2005 & 23,139 & 42.1 & 0.838 & 0.043 & 0.119 \\
\hline 2006 & 22,781 & 42.2 & 0.843 & 0.039 & 0.118 \\
\hline 2007 & 22,424 & 42.3 & 0.851 & 0.039 & 0.110 \\
\hline 2008 & 22,698 & 42.4 & 0.847 & 0.041 & 0.112 \\
\hline 2009 & 22,760 & 42.4 & 0.808 & 0.076 & 0.116 \\
\hline 2010 & 22,960 & 42.4 & 0.783 & 0.093 & 0.124 \\
\hline 2011 & 22,388 & 42.4 & 0.789 & 0.083 & 0.128 \\
\hline 2012 & 21,996 & 42.6 & 0.803 & 0.069 & 0.129 \\
\hline 2013 & 21,898 & 42.7 & 0.807 & 0.065 & 0.128 \\
\hline
\end{tabular}

Sources: IPUMS-CPS (Flood et al., 2015). Sample includes males 25-60 years old that appear in two consecutive months, and are matched using CPSIDP. Each row refers to January of that year. Age and employment state shares are computed using the final weights provided by the CPS

\section{B Relationship between $\Delta y$ and $\Delta x$}

To get a better picture of the relationship between earnings growth $\Delta y$ and changes in employment time $\Delta x$, we also plot the mean of $\Delta y$ conditional on $\Delta x$ in Figure A.1. 
Figure A.1: Conditional Mean of Earnings Growth, Italy 1996

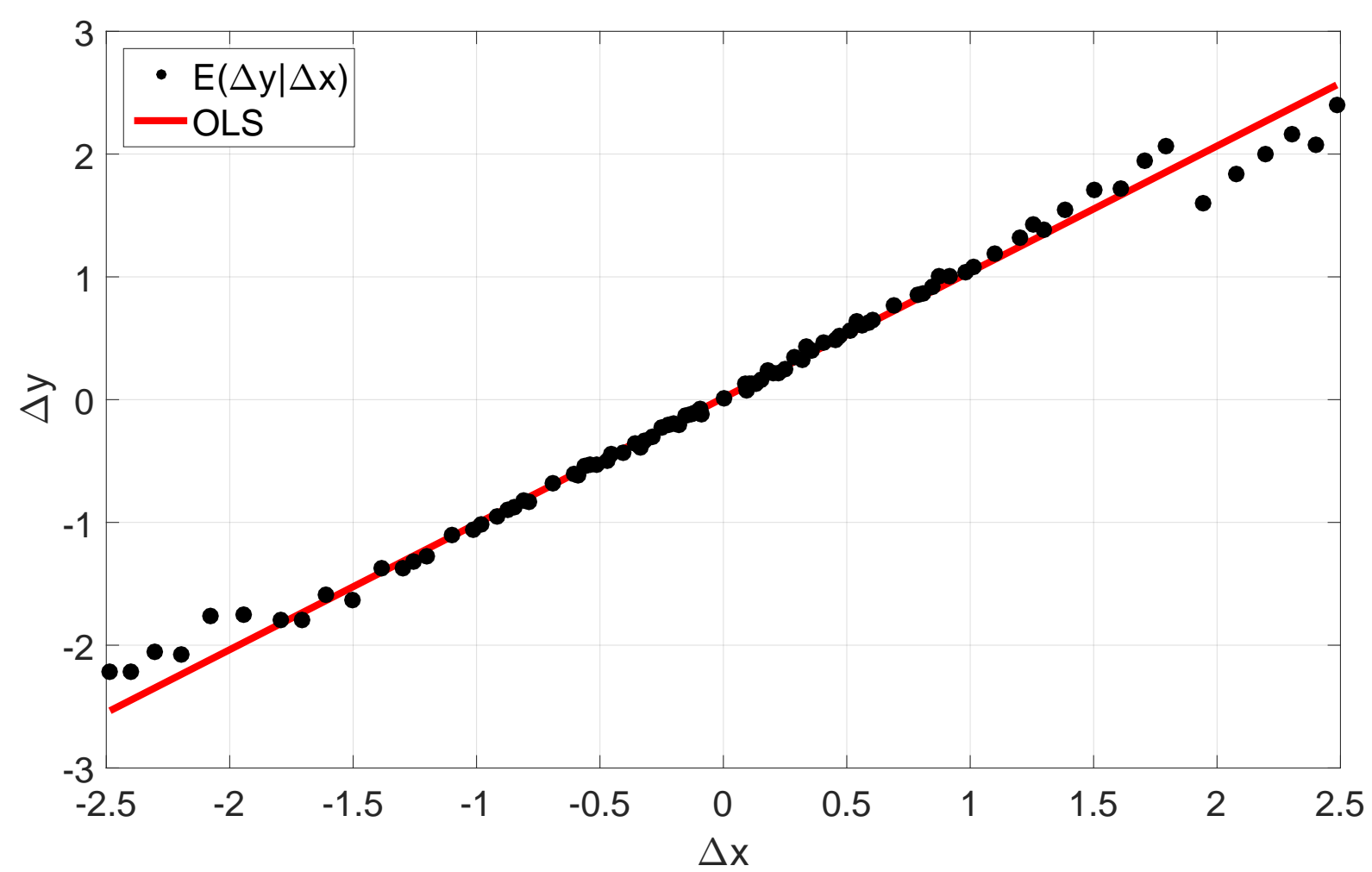

Notes: Dots show the sample mean of earnings growth $\Delta y$ within each discrete value of changes in employment time $\Delta x$. Red line shows the OLS regression $\Delta y_{i t}=\beta_{0}+\beta_{1} \Delta x_{i t}$. Sample is restricted to males 25-60 years old in 1996. Source: INPS, see details in text.

The conditional mean of the earnings growth for every value of changes in employment time non-parametrically captures the importance of non-linearities in the relationship between the two variables. The dots in Figure A.1 (referring to years 1995-1996) lie close to the regression line suggesting that the mean of changes in earnings rate, $\Delta w$, does not vary systematically across the support of $\Delta x$. The slope coefficient is 1.025 - close to 1 but statistically different.

\section{Statistical Model}

In this appendix we describe the statistical model used to transform the monthly labor flows data from the CPS, into cross-sectional distribution of annual changes in the employment time for every time period in the sample. The cross-sectional distribution is then used to generate the implied moments of changes in employment time, a component of earnings growth. 
A model based approach allows us to recover the distribution of changes in the extensive margin for the United States, despite the absence of a large representative panel of direct observation. This approach is, of course, not without cost. The suggested model imposes statistical restrictions, that allow us to identify the underlying process in a direct way. We will make the model assumptions and the implied restrictions transparent to the reader. To compensate for this drawback, the approach of using monthly flows data allows us to measure the distribution of annual employment changes at a monthly frequency, that is more adequate for documenting the business cycle. ${ }^{21}$

\section{C.1 Discrete Time Model}

Time is discrete (a month), and the labor market state follows a first order Markov chain. ${ }^{22}$ The individual state at period $t$ is denoted $s_{t}$, and takes on one of $\mathcal{S}=\{1,2, \ldots S\}$ discrete values (we drop individual $i$ notation in this section, for clarity). The probability of a worker who is in state $i$ at period $t-1$ to transition to state $j$ at period $t$ is given by:

$$
P_{i, j}(t)=\mathbb{P}\left(s_{t}=j \mid s_{t-1}=i\right)
$$

The transition probability matrix (TPM), in which every element $(i, j)$ of this matrix corresponds to the transition probability $P_{i, j}(t)$, is denoted $P(t)$. Since elements of the matrix represent probabilities, they all lie in the closed interval $[0,1]$, and every row sums up exactly to one.

We assume that a worker spends the whole period in the state $s_{t}$. For example, workers who are found to be employed in January will spend the whole period in employment.

In order to exploit the Markov property of conditional independence to compute annual changes in months worked, it will come handy to also define the reverse transition probability matrix $(\mathrm{rTPM}), \tilde{P}(t)$ :

$$
\tilde{P}_{i, j}(t)=\mathbb{P}\left(s_{t-1}=m \mid s_{t}=n\right)=P_{i, j}(t) \frac{\mathbb{P}\left(s_{t-1}=i\right)}{\mathbb{P}\left(s_{t}=j\right)}
$$

where the last equality is given by Bayes' rule. $\tilde{P}(t)$ is also a transition probability matrix, for a process in which time moves backwards. It retains all the Markov properties of the forward process, and it generates statistically identical sequence of transitions.

\section{C.2 The Conditional Annual Employment}

Invoking the Markov property, and conditional on the state at time $t$, we can use the sequence of TPMs and rTPMs to construct the full probability measure for any combination of months worked. We are specifically interested in finding the distribution of the number of months worked, a function of these sequences.

\footnotetext{
${ }^{21}$ According to the Business Cycle Dating Committee, recessions in post-war United States last 11.1 months on average. Thus, sampling at a 12 months frequency may not capture all the dynamics of idiosyncratic risk

${ }^{22}$ Technical background on occupation time in Markov chains, and some of the derivations can be found at Sericola (2000).
} 
Define $\mathcal{E} \subset \mathcal{S}$ the set of states which are considered employment, and $\mathcal{N}=\mathcal{S} \backslash \mathcal{E}$ the nonemployment states. Define $\vec{V}_{n}(t)$ as the counting process associated with the number of periods spent in employment from period $t$ onward, that is:

$$
\vec{V}_{n}(t)=\sum_{\tau=0}^{n-1} \mathbb{1}\left(s_{t+\tau} \in \mathcal{E}\right)
$$

For the sake of completeness, we also define $\overleftarrow{V}_{n}(t)$ as the reverse counting process, going from period $t-1$ backward. It retains the same properties as $\vec{V}_{n}(t)$.

We are now ready to define the joint probability mass functions over states and counts, $\vec{\Pi}_{i, j}(n, k, t)$ and $\overleftarrow{\Pi}_{i, j}(n, k, t)$ are defined by:

$$
\begin{aligned}
& \vec{\Pi}_{i, j}(n, k, t)=\mathbb{P}\left(\vec{V}_{n}(t)=k, s_{t}=j \mid s_{t-n}=i\right) \\
& \overleftarrow{\Pi}_{i, j}(n, k, t)=\mathbb{P}\left(\overleftarrow{V}_{n}(t)=k, s_{t-n}=j \mid s_{t}=i\right)
\end{aligned}
$$

where $\vec{\Pi}_{i, j}(n, k, t)$ stands for the probability to end up in state $j$ and with $k$ counts with a horizon of $n$ periods, conditional on being at state $i$ at time $t$ (similar interpretation is given to $\overleftarrow{\Pi}_{i, j}(n, k, t)$ ) By adding up these probabilities over $j$, we can get the marginal distribution of the number of months employed. The forward probability mass function of annual employment of a worker who is in state $i$ at time $t$, in the following 12 months, is given by:

$$
\vec{\Pi}_{i}(k, t)=\sum_{j=1}^{S} \Pi_{i, j}(12, k, t)
$$

Combining that with the backward probability mass function of annual employment, $\overleftarrow{\Pi}_{i}(k)$, we find the unconditional joint distribution of annual employment time using:

$$
\mathbb{P}\left(\tilde{V}_{12}(t)=k, V_{12}(t)=l\right)=\sum_{i, j} \overleftarrow{\Pi}_{i}(k, t) P_{i, j}(t) \vec{\Pi}_{j}(l, t)
$$

which is a direct application of the Markov assumption made earlier. The last and final step is to get the probability measure of the difference in logs, which is simple arithmetic transformation on the joint distribution.

\section{C.3 Computing the Forward Probability Mass Function}

We provide an algorithm to compute $\vec{\Pi}_{j}(\cdot)^{23}$. Without loss of generality, allow the set of employment states $\mathcal{E}$ to be the first states in $\mathcal{S}$, and the following to be the partition of $P(t)$ :

$$
P(t)=\left[\begin{array}{ll}
P_{\mathcal{E} \mathcal{E}}(t) & P_{\mathcal{E} \mathcal{N}}(t) \\
P_{\mathcal{N E}}(t) & P_{\mathcal{N N}}(t)
\end{array}\right]
$$

\footnotetext{
${ }^{23} \overleftarrow{\Pi}_{i}(\cdot)$ is solved using the same algorithm by replacing the TPMs with rTPMs and reversing the sequence order.
} 
In the same way as we partition $P(t)$, we can also partition $\vec{\Pi}(n, k, t)$, the matrix form of $\vec{\Pi}_{i, j}(n, k, t)$ :

$$
\vec{\Pi}(n, k, t)=\left[\begin{array}{ll}
\vec{\Pi}_{\mathcal{E E}}(n, k, t) & \vec{\Pi}_{\mathcal{E N}}(n, k, t) \\
\vec{\Pi}_{\mathcal{N E}}(n, k, t) & \vec{\Pi}_{\mathcal{N N}}(n, k, t)
\end{array}\right]
$$

We follow these notations with a proposition that recursively solves the forward probability density function of annual earnings.

Proposition 1 Let $\{P(t+\tau)\}_{\tau=1 \ldots 12}$ be the sequence of transition probability matrices, and let $\vec{\Pi}(n, k, t)$ be the matrix form of the joint probability mass function as defined in (20), then:

1. For every $n, k>0, \vec{\Pi}(n, k, t)$ can be recursively computed by:

$$
\begin{aligned}
{\left[\begin{array}{ll}
\vec{\Pi}_{\mathcal{E E}}(n, k, t) & \vec{\Pi}_{\mathcal{E N}}(n, k, t)
\end{array}\right]=\left[\begin{array}{ll}
P_{\mathcal{E} \mathcal{E}}(t+1) & P_{\mathcal{E N}}(t+1)
\end{array}\right] \cdot \vec{\Pi}(n-1, k-1, t+1) } \\
{\left[\begin{array}{ll}
\vec{\Pi}_{\mathcal{N E}}(n, k, t) & \vec{\Pi}_{\mathcal{N N}}(n, k, t)
\end{array}\right]=\left[\begin{array}{ll}
P_{\mathcal{N} \mathcal{E}}(t+1) & P_{\mathcal{N N}}(t+1)
\end{array}\right] \cdot \vec{\Pi}(n-1, k, t+1) }
\end{aligned}
$$

2. If $k=0$, for ever $n>0$,

$$
\vec{\Pi}(n, 0, t)=\left[\begin{array}{cc}
0 & 0 \\
0 & P_{\mathcal{N N}}(t+1)
\end{array}\right] \vec{\Pi}(n-1,0, t+1)
$$

3. If $n=0$, for every $k>0, \vec{\Pi}(0, k, t)=0$.

4. If $n=0$ and $k=0, \vec{\Pi}(0,0, t)=I_{S \times S}$

Proof. First consider the case where $n>0$ and $k>0$. If the state at $t$ is in $\mathcal{E}$, the worker spends that period in employment, and thus need to spend on $k-1$ out of the next $n-1$ periods in employment for employment time to be $k$. This implies equation (21). If the state at time $t$ is in $\mathcal{N}$, the worker is not employed, and so every path from $t+1$ must have $k$ employment periods within $n-1$ periods. This implies equation 22, completing step 1 . If $k=0$, the only paths that avoid employment are those that start within $\mathcal{N}$ and end up in $\mathcal{N}$. Applying the same logic as that used for step 1 , and imposing this restriction on the transition between $t$ and $t+1$ gives us step 2 . Step 3 is derived from the definition of $\vec{\Pi}$ : there can be at most n employment period in the next $n$ periods. Thus a path with $n=0$ and $k>0$ has zero probability. Finally, if $n=0$ transitions into a different state are not possible, and thus the probability on the diagonal is 1

Proposition 1 provides initial conditions and a recursion rule to exactly compute the crosssectional distribution of changes in the extensive margin. The transition probability matrices, that are the only source of variation over time, can be estimated directly and accurately from flows data, by dividing each flow by the stock at the destination state (forward) or origin state (backward).

\section{C.4 Limitation of the Markov Assumption}

The Markov assumption is used repeatedly in the solution described above. It allows us to use monthly matches, extracted from a short panel, to explore dynamics over much longer time horizons. This assumption is not without cost, since it imposes strict restrictions on the labor market state process. Namely, it imposes two limitations: ex-ante homogeneity, and no history dependence. 
Ex-ante homogeneity is the assumption that the distribution of future realization for two workers who are at the same state follows the same probability distribution. This may be a concern in particular when the data combines observations of workers from different occupations, education levels and age groups. No history dependence restricts future realization to depend only on the current state, but not on the path taken to this state. The main concern with restricting history dependence, is that some states tend to have a declining exit rates. It has been documented, for instance, that the rate of job finding declines with the duration of unemployment. ${ }^{24}$

These two limitations however, can be seen as restrictions imposed by the state space and by the observed data rather than by the Markov assumption. Ideally, having unlimited data, one could construct a rich enough state space to capture the full structure of an heterogeneous and history dependent process. For example, an exercise we conduct as a robustness check, is to stratify the sample into age groups and use age-group specific transition probability matrices. As long as these groups have enough observations to accurately measure flows, we can estimate the transition probability matrices and recover the unconditional distribution using the method above. A longer panel, including observations of annual income over several years, could allow conditioning on a particular path, or capture heterogeneity across income profiles as done in Guvenen et al. (2015).

\section{Robustness to Earnings Rate}

In this appendix we check whether replacing employment time with earnings rate returns the same results in the quantitative exercise laid out in Section 7. Table A.4 reports the results.

The moments of earnings rate are significant in mean and variance, but the coefficients on GDP growth do not move much when earnings rate is included. The coefficients on GDP growth in the regressions of the third moment and skewness remain approximately the same and significant. The coefficients on moments of earnings rate in these regressions are insignificant. This implies that changes in earnings rate cannot account for the cyclicality of earnings growth.

\footnotetext{
${ }^{24}$ This evidence can also be caused by unobserved ex-ante heterogeneity. See Heckman and Borjas (1980), Kiefer (1988) and Meyer (1990) for evidence and discussions on heterogeneity versus path dependence.
} 
Table A.4: Accounting for Cyclicality of Earnings Growth - Earnings Rate

\begin{tabular}{|c|c|c|c|c|c|c|}
\hline & \multicolumn{6}{|c|}{$\Delta x \operatorname{Vs} \Delta w$} \\
\hline & \multicolumn{3}{|c|}{ Mean } & \multicolumn{3}{|c|}{ Variance } \\
\hline & $(1)$ & $(2)$ & $(3)$ & (4) & $(5)$ & $(6)$ \\
\hline \multirow[t]{2}{*}{ GDP Growth } & 0.716 & 0.066 & 0.437 & -0.327 & -0.152 & -0.356 \\
\hline & $(0.140)$ & $(0.159)$ & $(0.082)$ & $(0.189)$ & $(0.143)$ & $(0.112)$ \\
\hline \multirow[t]{2}{*}{ Employment Time $(\Delta x)$} & & 0.825 & & & 0.680 & \\
\hline & & $(0.159)$ & & & $(0.143)$ & \\
\hline \multirow[t]{2}{*}{ Earnings Rate $(\Delta w)$} & & & 0.658 & & & 0.772 \\
\hline & & & $(0.082)$ & & & $(0.112)$ \\
\hline R-squared & 0.51 & 0.77 & 0.87 & 0.11 & 0.54 & 0.70 \\
\hline Observations & 27 & 27 & 27 & 27 & 27 & 27 \\
\hline
\end{tabular}

\begin{tabular}{|c|c|c|c|c|c|c|}
\hline & \multicolumn{6}{|c|}{$\Delta x \operatorname{Vs} \Delta w$} \\
\hline & \multicolumn{3}{|c|}{ Third Moment } & \multicolumn{3}{|c|}{ Skewness } \\
\hline & (1) & (2) & (3) & (4) & (5) & (6) \\
\hline \multirow{2}{*}{ GDP Growth } & 0.639 & -0.122 & 0.633 & 0.606 & -0.096 & 0.575 \\
\hline & $(0.154)$ & $(0.133)$ & $(0.148)$ & $(0.159)$ & $(0.138)$ & $(0.151)$ \\
\hline \multirow[t]{2}{*}{ Employment Time $(\Delta x)$} & & 0.996 & & & 0.957 & \\
\hline & & $(0.133)$ & & & $(0.138)$ & \\
\hline \multirow[t]{2}{*}{ Earnings Rate $(\Delta w)$} & & & 0.256 & & & 0.305 \\
\hline & & & $(0.148)$ & & & $(0.151)$ \\
\hline R-squared & 0.41 & 0.82 & 0.47 & 0.37 & 0.79 & 0.46 \\
\hline Observations & 27 & 27 & 27 & 27 & 27 & 27 \\
\hline
\end{tabular}

Notes: The dependent variables are moments of earnings growth reported in the title of each panel. Standard errors are reported in parentheses. Coefficients in bold are significant at the 5 percent level. The control variables are GDP growth and moments of changes in earnings rate. All the time series are detrended and standardized. 